\title{
Modelling of non-linear CHP efficiency curves in distributed energy systems
}

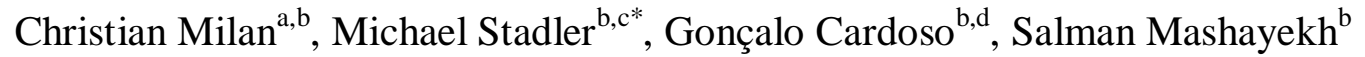 \\ ${ }^{a}$ Department of Energy Technology, Aalborg University, Pontoppidanstræde 101, 9220 \\ Aalborg, Denmark \\ b Lawrence Berkeley National Laboratory, University of California, 1 Cyclotron Rd, \\ Berkeley, CA, USA \\ ${ }^{c}$ Center for Energy and innovative Technologies (CET), Doberggasse 9, 3681 Hofamt Priel, \\ Austria \\ ${ }^{\mathrm{d}}$ Instituto Superior Técnico, University of Lisbon, Avenida Rovisco Pais 1, 1049-001 Lisboa, \\ Portugal
}

\begin{abstract}
Distributed energy resources gain an increased importance in commercial and industrial building design. Combined heat and power (CHP) units are considered as one of the key technologies for cost and emission reduction in buildings. In order to make optimal decisions on investment and operation for these technologies, detailed system models are needed. These models are often formulated as linear programming problems to keep computational costs and complexity in a reasonable range. However, CHP systems involve variations of the efficiency for large nameplate capacity ranges and in case of part load operation, which can be even of non-linear nature. Since considering these characteristics would turn the models into nonlinear problems, in most cases only constant efficiencies are assumed. This paper proposes possible solutions to address this issue. For a mixed integer linear programming problem two approaches are formulated using binary and Special-Ordered-Set (SOS) variables. Both suggestions have been implemented into the optimization model DER-CAM to simulate investment decisions of CHP micro-turbines and CHP fuel cells with variable efficiencies. The approaches have further been applied successfully in a case study with four different commercial buildings. Comparison of the results between the standard version and the new approaches indicate that total annual system costs remain almost unchanged. System performance is subject to change and storage technologies become more important. Part load operation has mainly been found important for fuel cell units. The micro-turbine is found almost exclusively in full load, thus rendering the application of the new approaches for this technology unnecessary for the considered unit sizes and building types. The approach using binary variables was the most promising method to model variable efficiencies in terms of computational costs and results. It should especially be considered for specific fuel cell technologies. Further investigation on the impacts of this approach on the prediction of fuel cell and micro-turbine performance is suggested.
\end{abstract}

Keywords: renewable energy supply system, non-linear optimization, linearization, microgrid modelling, distributed energy resources, combined heat and power (CHP)

\section{Nomenclature}

\section{Subscripts}

Bat Electric Vehicle Battery

\footnotetext{
* Corresponding author. Tel.: +1 (510) 486-4929 or +43 (0)664 7390-7185. E-mail address: MStadler@lbl.gov or MStadler@cet.or.at (M. Stadler).
} 


$\begin{array}{ll}\text { DER } & \text { Distributed Energy Resources } \\ D R & \text { Demand response } \\ e l & \text { electricity } \\ n & \text { capacity sizes index } \\ \text { inst } & \text { installed } \\ m & \text { operational load level index } \\ k & \text { number of units index } \\ M & \text { number of capacity sizes } \\ N & \text { number of operational load levels } \\ t & \text { time index } \\ \mathrm{T} & \text { number of time steps }\end{array}$

\section{Superscripts}

$\wedge \quad$ tabled value

\section{Dependent Variables}

$\begin{array}{ll}\alpha & \text { heat to power ratio } \\ C & \text { system costs } \\ E & \text { system emissions } \\ E V & \text { electric vehicle } \\ \eta & \text { efficiency } \\ F & \text { fuel consumption } \\ I & \text { income from energy sales } \\ v & \text { weighting variable (binary variable) } \\ \omega & \text { weighting variable (binary variable) } \\ x & \text { weighting variable (type SOS2) } \\ y & \text { weighting variable (type SOS1) }\end{array}$

\section{Decision Variables}

$\begin{array}{ll}P & \text { unit capacity } \\ U & \text { operational load level }\end{array}$

\section{Introduction}

Optimizing building energy supply systems with high temporal resolution over a large timespan - usually one year of hourly time steps - can result in mathematically complex problems with long calculation procedures before reaching optimal solutions. In order to keep computational efforts within reasonable levels several simplifications and assumptions are commonly used. Such simplifications can include those used in linear models that guarantee convergence and optimality, albeit sometimes at the cost of significant adverse impacts on model accuracy [1]. Looking at energy systems models specifically, a common approximation used concerns the efficiency of conventional power generation technologies, which in most cases is treated as a constant. This approximation might be close to reality for some technologies and operating conditions, but a very rough simplification for others. This paper will address this topic by modeling efficiency curves of conventional power generation technologies with different levels of accuracy, as we will discuss later in the paper.

Using Combined Heat and Power (CHP) for energy supply is very often a sustainable and economic strategy to reduce fuel demand, and CHP technologies are among the most promising solutions for fuel saving, emission reduction, and fossil fuel independency [1]-[3]. 
However, the economic convenience of CHP systems depends on the specific conditions under which they operate, since their performance significantly changes when operating in partial load [1]-[6]. The electrical and thermal efficiencies of CHP units depend on the technology, unit size (capacity), and loading conditions (operating point). M. Bianchi et al. [1] report that the nameplate electric efficiency and thermal efficiency at maximum recovered thermal power can range between 10\%-30\%, and respectively 40\%-90\%. Moreover, their electric efficiency in partial loads can degrade more than $20 \%$ compared to the full load efficiency. Higher partial load efficiency variations are also reported in [7]. CHP systems have potential to be used in various applications such as residential buildings, hospitals, and supermarkets, whose electrical, thermal, and cooling demand are time-variant [1]. Application of CHP technologies in time-varying demand environments along with their partial load efficiency variations signifies the importance of modelling these technologies with load dependent efficiencies.

To model and analyze the impact of partial load efficiencies for CHP technologies in an optimal DER investment problem, this paper proposes two linear approaches. Both approaches allow for integrating nonlinear efficiency curves into the optimization problem without abandoning the problem linearity. This type of modeling and analysis has not been carried out in the past. To model DER efficiencies (CHP technologies in particular), researchers either use constant efficiencies to simplify their model and keep it linear, or consider nonlinear efficiencies in nonlinear models. While the former approach may result in non-optimal results due to over-simplification, the latter may not be able to find the global optimum solution, may not find a solution at all due to the complexity of the resulting model, or increase the computational costs dramatically.

Some examples of the models using constant efficiencies for CHP technologies are given in [8]-[16] . Milan et al. [8] propose an investment planning methodology to minimize total costs of $100 \%$ DER-based supply systems, considering the interdependencies between different supply technologies, for both Net Zero Energy Buildings (Net ZEB) and Low Energy Buildings (LEB). They formulate the problem as a Mixed Integer Linear Program (MILP). As in most of the similar models, the output from this model suggests optimal sizes of supply technologies and/or building load reduction measures, and proposed operational schedules. To simplify the model, constant CHP efficiencies are used in this work. Münster et al. [9] analyze the competition between district heating and other types of individual heating, and use also constant efficiencies to perform the analysis. The work in this paper is motivated by the increase in the attractiveness of individual solutions provided by the new technologies such as electric heating, heat pumps, and micro-CHP. In a similar application, Lund et al. [10] study different district and individual heating options for Denmark, and use constant efficiencies for the studies. Liu et al. [11] present a framework for optimal design of energy systems in commercial buildings, which aims to improve energy efficiency and environmental performance. They develop a multi-objective mixed-integer optimization problem to address the two economic and environmental objectives, and use constant efficiencies for all technologies. Similarly, Ren et al. [12] propose a MILP model for the planning and evaluation of DER systems, which delivers the optimal DER technologies to be installed and the optimal operation schedules, given the site's energy loads, weather conditions, tariff structure, and candidate DER technology characteristics. In this model, again only constant efficiencies are considered for all DER technologies, including the ones with heat recovery capabilities. Hawkes et al. [13] develop a linear model for the high level microgrid system design, including generator and storage unit commitment, to minimize the cost. A constant efficiency is considered for the CHP units in this model. In another work in [14], a mixed integer linear 
programming model is developed for long-term optimization of cogeneration systems, which uses load-independent fixed efficiencies.

Cho et al. [15] present an optimal energy dispatch algorithm that minimizes the cost of electric and natural gas energies. This work develops a linear programming model with cooling, heating, and electrical load demand constraints and constraints of Combined Cooling, Heating, and Power (CCHP) components' efficiencies. In this model, the efficiency of each CCHP component is assumed to be constant. Also, in another work in [16], Cho et al. present results from operation optimization of CCHP systems for various climate conditions, which aims to reduce operational costs, primary energy consumption, and carbon dioxide emissions. In this work, they assume a linear behaviour with a constant slope for the electricity output to fuel ratio, thus constant efficiencies. To avoid "on/off" constraints in their MILP model, they use two LP simulations and choose the smallest output value.

There are also some research works that use non-fixed partial load efficiency models for CHP technologies, but do not keep the problem linear and use nonlinear formulations. Such examples are common in combined heat and power economic dispatch formulations, such as [17]-[23]. For the fuel consumption of a CHP unit in these formulations, convex quadratic functions in both output power and output heat of the unit are used, which result in nonlinear formulations. To solve the resulting nonlinear optimization problems, heuristic methods are commonly applied, e.g. Particle Swarm Optimization (PSO) [17], [18], Teaching Learning Based Optimization (TLBO) [19], Mesh Adaptive Direct Search (MADS) [20], and Cuckoo Search Algorithm [21]. Heuristic optimization methods, especially for large-scale optimization problems, are not guaranteed to find a solution and the solution they find may not be the global solution. Hence in large-scale optimization problems with millions of decision variables, such as the ones discussed in this paper, linear problem formulations are highly preferred over nonlinear ones.

This paper presents two piecewise linear approximation methods for nonlinear DER efficiency curves. Both suggestions have been implemented in the optimization model DERCAM (Distributed Energy Resources and Customer Adoption Model), which traditionally used fixed efficiencies for CHP micro-turbine and fuel cell technologies [24]-[26]. DERCAM is a decision support tool for decentralized energy systems developed by the Lawrence Berkeley National Laboratory (LBNL). It is formulated as a Mixed-Integer Linear Program (MILP), and implemented in the General Algebraic Modeling System (GAMS). DER-CAM has two main versions, i.e. the Investment and Planning DER-CAM, and the Operations DER-CAM. The Investment and Planning DER-CAM picks optimal microgrid/building equipment combinations and sizes, and their corresponding dispatch, using three day types per month to represent a year of historic hourly energy loads, technology costs and performance, fuel prices, historic weather data, and the utility tariff. The Operations DERCAM is used for microgrid/building dispatch optimization for a given period, typically several days to a week ahead, with a time resolution of 5 minutes, 15 minutes, or 1 hour, using weather and load forecast for the optimization period, and assuming a known technology portfolio [27]. This work uses the Investment and Planning version of DER-CAM.

The contributions of this paper are twofold. First, to address the problem of including nonlinear efficiencies in DER optimization problems, without scarifying the problem linearity, this paper proposes two alternative stepwise methods to approximate twodimensional non-linear DER efficiency curves. In the first method, binary variables are used to approximate nonlinear efficiency curves with piecewise linear ones. In the second method, 
Special-Ordered-Set (SOS) variables are used to approximate the nonlinear efficiency curves. SOS variables are defined as consecutive, ordered sets of variables, where no more than one or two (based on SOS type) adjacent elements in the ordered set can take non-zero values. The problem formulation resulting from the former method can be solved by any solver capable of solving mixed-integer linear problems. On the contrary, the latter method results in a formulation that can only be solved by solvers recognizing SOS variables. The performance of these two methods is investigated in detail by applying them in a case study consisting of four different buildings. The second contribution of this paper is in analyzing the impact of considering nonlinear DER efficiency curves of three relevant technologies on the final solution and recommending best practices for including such nonlinear efficiency curves for other similar problems.

The structure of the following parts of the paper is as follows:

- Section 2 describes the optimization model DER-CAM which was adapted in this paper.

- Section 3 discusses the efficiency characteristics of DER technologies in terms of installed capacity and part load.

- Section 4 introduces the theory for two linearization approaches of non-linear efficiency curves.

- Section 5 presents the case study performed together with the modifications undertaken in DER-CAM and detailed results.

- Section 6 summarizes the main findings of the case study and gives recommendations for further action.

\section{DER-CAM}

The Distributed Energy Resources Customer Adoption Model (DER-CAM) is a decision support tool developed at Lawrence Berkeley National Laboratory with the purpose of optimizing DER investment and operation decisions in microgrids and building energy supply systems. The model is formulated as a mixed integer linear program (MILP), and being firstly introduced in the year 2000 it has been constantly extended and applied throughout several dozen case studies [28]-[33]. Currently, DER-CAM features two main branches: one to optimize investment decisions based on historic information - Investment \& Planning DER-CAM, and a second one to determine optimal operational schedules of installed equipment and for predictive microgrid controller design, based on weather and load forecasts - Operations DER-CAM. Investment \& Planning DER-CAM is publicly available through a web-based interface [28] and will be the reference for further discussions on DER-CAM in this work.

Once detailed load profiles are known, such as demand data for space heating, hot water, cooling, and electricity, DER-CAM determines the optimal installed capacity of DER technologies with respect to a user-defined objective function, generally economic and/or environmental. Key input data also includes electricity and natural gas tariffs, and prices on relevant fuels and financial subsidies, if applicable. For all considered DER technologies, performance models are implemented based on state-of-the-art technical specifications, namely with regards to efficiencies and heat-to-power ratios. Moreover, detailed cost data for investment, operation and maintenance of each DER unit are considered in the model. In order to solve the DER investment problem, DER-CAM determines on an hourly basis the optimal scheduling of the candidate energy supply system for one reference year. Therefore, investment decisions are based on a bottom up approach and results will also include detailed 
operational schedules for all selected technologies, along with key variables such as total annual energy costs and $\mathrm{CO}_{2}$ emissions.

The hourly system performance is based on detailed energy balances. Fig. 1 indicates the energy resources, energy flows and end-uses implemented in DER-CAM in the form of a SANKEY diagram [26]. This provides a full view of energy flows in the form of arrows from possible resources considered within the optimization and how they relate to consumption.

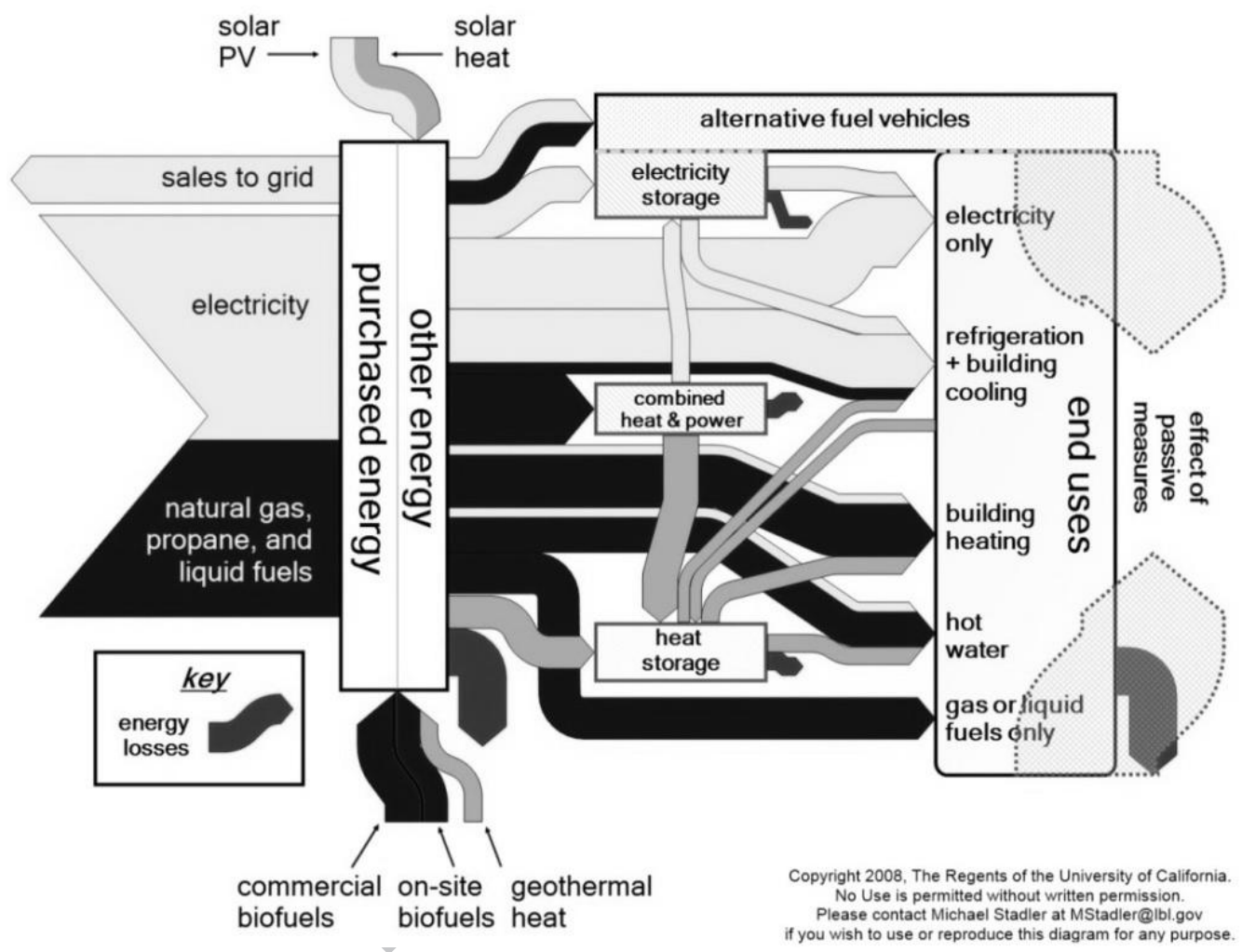

Fig. 1. SANKEY diagram indicating energy flows in DER-CAM [26]

Energy sources considered in DER-CAM include utility natural gas, biofuels, solar radiation, utility electricity, and geothermal heat. Dark shaded arrows in Fig. 1 represent natural gas and biofuels. Light grey shaded arrows represent electricity, and the dark grey colour stands for heat and recoverable waste heat. DER-CAM identifies the optimal system configuration in terms of costs and/or environmental impact, while meeting all shown energy demands on the right side of the diagram, defined for each hourly time step in a given site. Similarly to consumption profiles, on-site resource availability such as solar radiation and other boundary conditions can be highly fluctuating, and the energy flows for each carrier might reflect these fluctuations accordingly.

The key generation options in DER-CAM are CHP technologies, which interconnect supply and storage of electricity and heat, although other options such as photovoltaic and solar thermal panels are available. Recently, DER-CAM has also been extended to consider electric vehicles for vehicle-to-building services [34], and several other features are currently under development.

DER-CAM allows a flexible objective function definition, such as minimizing total annual energy costs, $\mathrm{CO}_{2}$ emissions, net energy minimization, or combinations of them. Eq. 1 defines the objective function for cost optimization: 
$\min f_{\text {costs }}\left(P_{\text {inst }}, U_{t}\right)=C_{\text {total }}=C_{e l}+C_{D E R}+C_{f u e l}+C_{D R}+C_{B a t}-I$

The total annual energy costs $C_{\text {total }}$ depend on the installed capacity of DER technologies, $P_{\text {inst }}$, and their operational level $U_{t}$ at each hour $t$. These variables have impacts on the electricity costs $C_{e l}$, on the amortized installation and maintenance costs of DER components $C_{D E R}$, on fuel costs $C_{f u e l}$, on costs of adopting demand response measures $C_{D R}$, and also on electric vehicle battery degradation costs due to interactions with the building energy supply system $C_{B a t}$, although electric vehicles are not considered in this work. Moreover, income generated by energy sales to public networks $I$ is subtracted from the total costs.

The objective function for the minimization of $\mathrm{CO}_{2}$ emissions is formulated according to Eq. 2:

$\operatorname{minf}_{\mathrm{CO}_{2}}\left(P_{\text {inst }}, U_{t}\right)=E_{\mathrm{CO}_{2} \text {,total }}=E_{\mathrm{CO}_{2}, \text { el }}+E_{\mathrm{CO}_{2}, \text { fuel }}+E_{\mathrm{CO}_{2}, \mathrm{EV}}$

Similarly to annual energy costs, the total annual $\mathrm{CO}_{2}$ emissions $E_{C O 2 \text {, total }}$ are a function of installed DER capacity and operational schedules. They are defined in DER-CAM as the sum of $\mathrm{CO}_{2}$ emissions related to the generation of grid-supplied electricity, emissions caused by onsite fuel consumption $E_{\mathrm{CO} \text {,fuel }}$, and $\mathrm{CO}_{2}$ emissions caused by electric vehicle charging $E_{\mathrm{CO} \text {, }}$, ${ }_{E V}$ (not considered in this work).

Schematically, the formulation implemented in DER-CAM can be described according to Fig. 2 .

\begin{tabular}{|c|c|c|c|}
\hline \multirow{4}{*}{$\begin{array}{l}\text { min } \mathbf{f}=\text { TotalEnergyCosts } \\
\text { (or COZemissions) } \\
\text { = FixedutilityCosts } \\
\text { + VolumetricUtilityCosts } \\
\text { + PowerUtilityCosts } \\
\text { + AnnualizedInvestment Costs } \\
\text { + Fuel Costs } \\
\text { + OsMCosts } \\
\text { + LoadManagement Costs } \\
\text { - Sales } \\
+\ldots\end{array}$} & energy balance is guaranteed & operational constrains are met & financial constrains are met \\
\hline & $\begin{array}{l}\text { UtilityPurchase } \\
+ \text { OnSit eGeneration } \\
+ \text { StorageO utput } \\
= \\
\text { ClientLoads } \\
+ \text { StorageInput }\end{array}$ & $\begin{array}{l}\text { OnSiteGeneration } \\
+ \text { ExportsGeneration } \\
<= \\
\text { Capacity } \\
\text { EnergyStored(t) }\end{array}$ & $\begin{array}{l}\text { AnnualSavings } \\
= \\
\text { BaseCaseCost } \\
\text { - } \\
\text { (TotalEnergyCost } \\
\text { - AnnualizedInvestmentCosts) }\end{array}$ \\
\hline & $\begin{array}{l}\text { + LoadŚhifting } \\
\text { - DemandResponse }\end{array}$ & $\begin{array}{l}= \\
\text { EnergyStored(t-1) * (1 - LossCoef) } \\
+ \text { StorageInput(t) * ChargeEIf } \\
\text { - StorageOutput(t) / DischargeEff }\end{array}$ & $\begin{array}{l}\text { AnnualSavings } \\
>= \\
\text { Totall nvestmentCosts } \\
\text { / MaxPayBackPeriod }\end{array}$ \\
\hline & & $\cdots$ & $\ldots$ \\
\hline
\end{tabular}

Fig. 2. Schematic representation of DER-CAM

Several assumptions and simplifications are applied in DER-CAM to model technology performance and customer decisions. It is estimated that the customer bases his investment and operation strategy solely on optimizing the direct economic benefit, $\mathrm{CO}_{2}$ reductions, or a combination of both. Concerning the technologies, constant efficiencies are assumed for the operation throughout the whole component lifetime without considering possible output declines. Furthermore, start-up and ramping restrictions of supply units are not considered, as well as reliabilities and power quality benefits.

Researching the impact of assuming constant efficiencies for supply components is the objective of this work. In the following chapters relevant technologies will be identified and two approaches are described to address this issue. Furthermore, the extension of the Investment \& Planning version of DER-CAM is presented in order to implement these approaches. 


\section{Efficiencies of DER-Technologies}

Typically, it can be stated that the maximal electrical efficiency $\eta_{e l, m a x}$ of DER technologies depends on two key factors: the installed unit capacity $P_{\text {inst }}$, and the operating load level at a given time $U_{t}$ :

$\eta_{e l}=f\left(P_{\text {inst }}, U_{t}\right)$

In Fig. 3, the maximal electrical efficiency of natural gas powered Internal Combustion Engines (ICE) is shown for different unit sizes. This relation is based on data from [35], which gathered and analysed data from several hundred market available units of different sizes in Germany. The figure illustrates significantly lower efficiencies for small capacities and a non-linear relationship in the depicted range between the installed electrical power and the maximal efficiency.

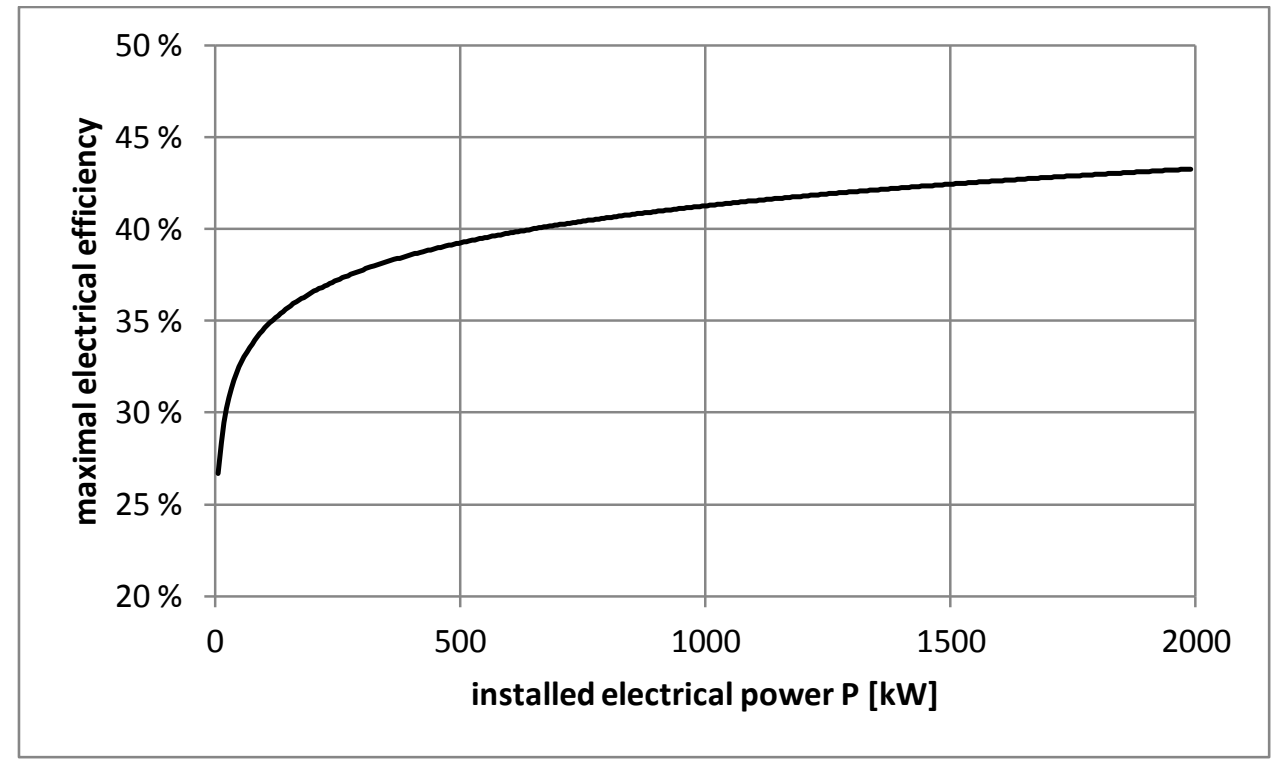

Fig. 3. Maximal electrical efficiencies for natural gas powered ICEs [35]

It should be noted that the graph in Fig. 3 is heavily dependent on the fuel and only valid for natural gas powered plans. For other fuels, e.g. diesel, different characteristics may apply and the relation between installed power and maximum electrical efficiency can be close to linear behaviour for certain fuel types [35].

Besides the installed capacity, the operational load level $U_{t}$ also influences the efficiency of certain technologies. Fig. 4 depicts the part load performance of a typical natural gas powered ICE based on data given in [36]. As in Fig. 3, a non-linear correlation can be observed. 


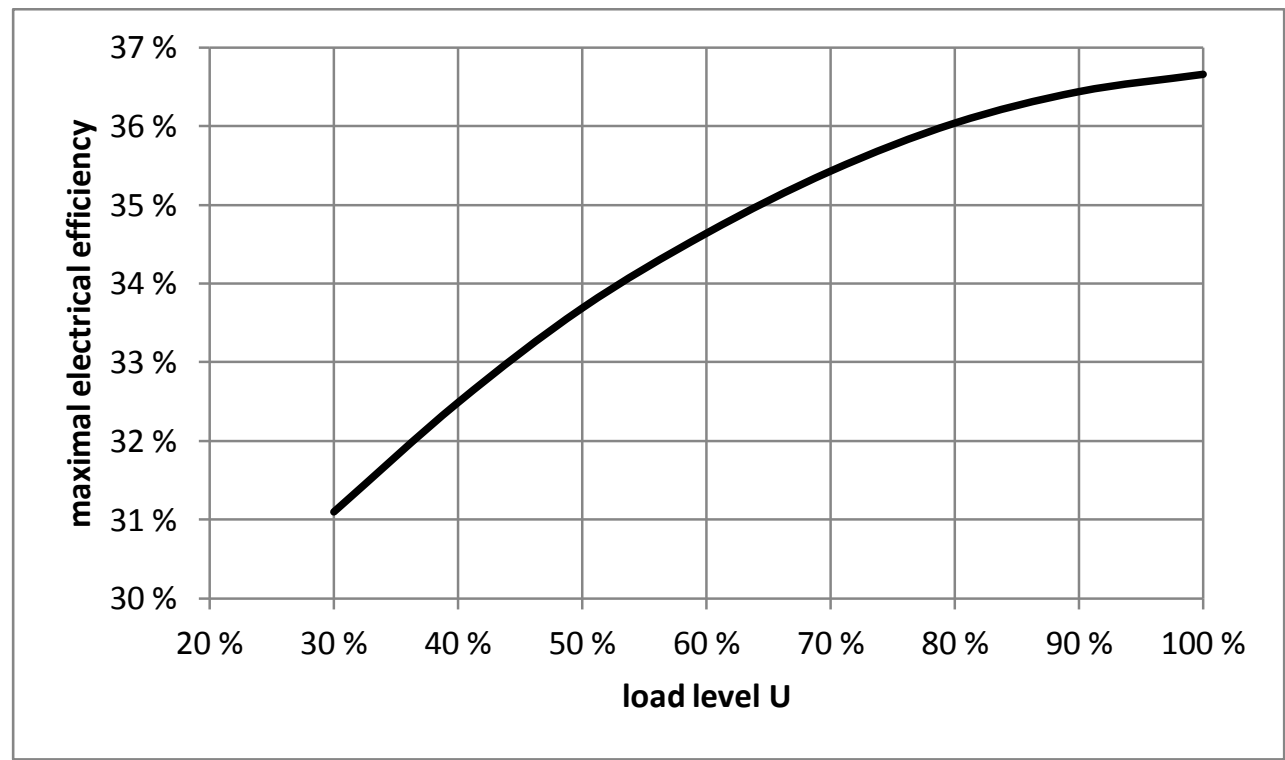

Fig. 4. Electrical efficiencies for a typical natural gas powered ICE in part load [36]

Based on these observations, considering variable efficiencies results in a two-dimensional non-linear problem when selecting the optimal unit sizes to meet energy demand in a given building or microgrid, although this dependency is not valid for all technologies.

Table 1 lists relevant supply technologies considered in DER-CAM, indicating whether or not they exhibit considerable efficiency variations during part load operation, and if they were considered in the developments introduced by this work.

From the seven technologies listed, all combustion technologies and fuel cells have part load characteristics. The maximal efficiencies of photovoltaic panels (PV), solar thermal collectors (ST), and heat pumps (HP) do not differ significantly on part load conditions or on installed capacity.

Table 1. Relevant technologies in DER-CAM with part-load classification

\begin{tabular}{ccc}
\hline Technology & Variable part load efficiency & Included in this work \\
\hline Photovoltaic & no & - \\
Solar Thermal Collector & no & - \\
Heat Pump & no & - \\
Fuel Cell (FC) & yes & yes \\
Internal Combustion Engine & yes & yes \\
(ICE) & yes & yes \\
Micro-turbine (MT) & yes & no \\
Gas Turbine &
\end{tabular}

The developments introduced in this work regarding variable efficiencies focus on Fuel Cells (FC), Internal Combustion Engines (ICE) and Micro-turbines (MT), as Gas Turbines are typically available in large capacity sizes and are not the focus of this work. 


\section{Modelling two-dimensional non-linear efficiency curves}

Since efficiencies are directly dependent on the installed capacity $P_{\text {inst }}$ and operational load level $U_{t}$, both parameters can be identified as the decision variables defining the energy conversion capability of a unit over time. $P_{\text {inst }}$ and $U_{t}$ influence the conversion efficiency, the fuel consumption $F_{t}$ and, if connected to a heat exchanger in a CHP system, the heat output $P_{\text {heat }, t}$. Since the load level $U_{t}$ can change for each point in time, the functions are dependent on the time index $t$ as shown in Eqs. 4 to 6, where $P_{\text {inst }}$ and $U_{t}$ refer to the electrical output in all equations:

$P_{e l, t}=P_{\text {inst }} * U_{t}$

$F_{t}=\left(P_{\text {inst }} * U_{t}\right) / \eta_{e l, t}$

$P_{\text {heat }, t}=P_{\text {inst }} * U_{t} * \alpha_{t}$

with $\alpha_{\mathrm{t}}$ being the heat to power ratio defined as in Eq. 7:

$\alpha_{\mathrm{t}}=\eta_{\text {heat }, t} / \eta_{e l, t}$

and $\eta_{e l, t}$ being a function of $P_{\text {inst }}$ and $U_{t}$.

Even though the efficiency curves shown in Fig. 3 and 4 can be linearized using the approaches presented later in this paper, one should be aware of that all three variables $P_{e l, t}, F_{t}$ and $P_{\text {heat, } t}$ are dependent on the product of $P_{\text {inst }}$ and $U_{t}$. Their calculation after the determination of these two decision variables would create an additional non-linear problem. For this reason all values for $P_{e l, t}, F_{t}$ and $P_{\text {heat }, t}$ are calculated beforehand for the range of possible installed capacities and operational load levels. Table 2 shows electrical efficiencies of a natural gas powered ICE for two installed capacities and several load levels. The values are based on data given in [36].

Table 2. Electrical efficiencies of natural gas powered ICE [36]

\begin{tabular}{l|lllllllll}
\hline & \multicolumn{10}{|c}{ Load level, $U_{m, t}$} \\
\cline { 2 - 10 } Installed capacity & $U_{1, t}$ & $U_{2, t}$ & $U_{3, t}$ & $U_{4, t}$ & $U_{5, t}$ & $U_{6, t}$ & $U_{7, t}$ & $U_{8, t}$ & $U_{9, t}$ \\
option, $P_{\text {inst }, n}$ & $0 \%$ & $30 \%$ & $40 \%$ & $50 \%$ & $60 \%$ & $70 \%$ & $80 \%$ & $90 \%$ & $100 \%$ \\
\hline$P_{\text {inst }, 1} \quad 60 \mathrm{~kW}$ & 0 & 0.246 & 0.257 & 0.267 & 0.274 & 0.28 & 0.285 & 0.288 & 0.29 \\
$P_{\text {inst }, 2} \quad 250 \mathrm{~kW}$ & 0 & 0.255 & 0.266 & 0.276 & 0.283 & 0.29 & 0.295 & 0.298 & 0.30 \\
\hline
\end{tabular}

From now on tabled values will be marked with a circumflex $\left(^{\wedge}\right)$ and the indices ${ }_{n}$ and ${ }_{m}$ will refer to elements in the set of the discrete installed capacity options and to considered load levels, respectively. The tables for $P_{e l, t}, F_{t}$ and $P_{\text {heat, } t}$ form the basis for two approaches, which allow linearizing and approximating two-dimensional non-linear efficiency curves into MILPs. Both approaches will be elaborated in the following sections.

\subsection{Approach 1 - Linearization using binary variables}

The first approach is based on binary variables, which are used to form classes with each class containing a certain tabled value. Fig. 5 shows the principle equations and their relationship for the binary approach. 


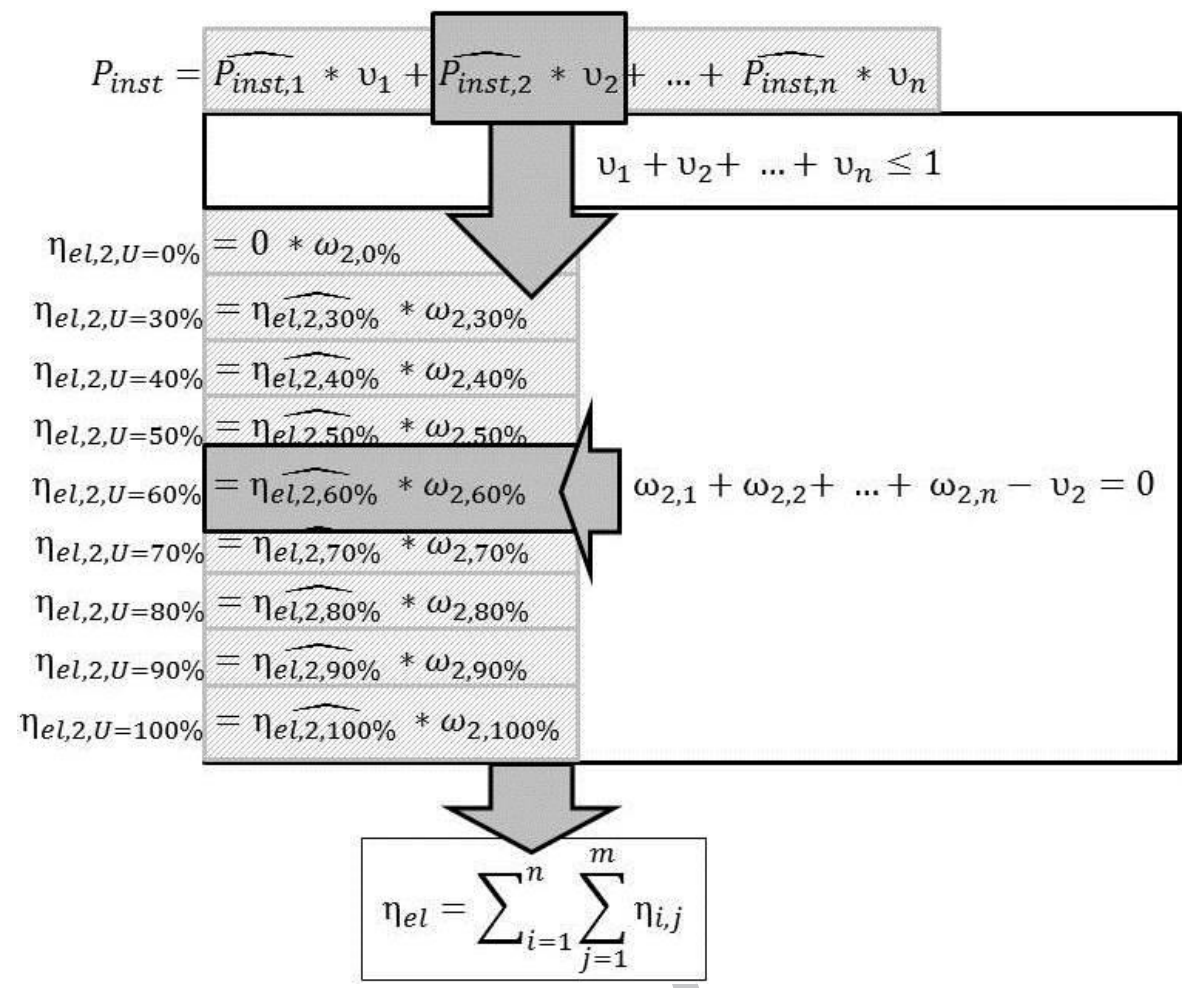

Fig. 5. Schematic of the binary approach choosing efficiencies based on installed capacity and operational load level at each time step $t$

The decision on the installed capacity is guaranteed by Eq. 8, which consists on the summation over the product of tabled capacities options $P_{i n s t, n}$ with a corresponding binary variable for each option:

$P_{\text {inst }}=\Sigma_{n}\left(P^{\wedge}{ }_{\text {inst }, n} * v_{n}\right)$

The index $n$ refers to the nameplate capacity specified beforehand in the data table with $N$ indicating the number of tabled sizes.

In order to assure that only one capacity is chosen, the constraint in Eq. 9 is introduced. Also, it should be noted that since the investment decision is not time-dependent, these equations hold for the entire calculation process.

$\Sigma_{n} v_{n} \leq 1$

The operational level of the installed capacity option $n$ in each time step $t$ is determined by Eq. 10, where the binary variable $v_{n}$ guarantees the lookup is made on the appropriate capacity option, and the binary variable $\omega_{n, m, t}$ guarantees that only one operating point is selected in each time step:

$\Sigma_{m}\left(\omega_{n, m, t}\right)-v_{n}=0$ for $\mathrm{n}=\{1,2, \ldots, \mathrm{N}\}$ and $\mathrm{t}=\{1,2, \ldots, \mathrm{T}\}$

Thus, solving Eq. 10 over time determines the operation point $m, t$ for installed capacity option $n$, for which efficiency, fuel consumption, and power output can be determined based on the tabled values, as shown below for electric efficiency:

$\eta_{e l, n, m, t}=\eta^{\wedge} e_{l, n, m} * \omega_{n, m, t}$ for $\mathrm{n}=\{1,2, \ldots, \mathrm{N}\}, \mathrm{m}=\{1,2, \ldots, \mathrm{M}\}$ and $\mathrm{t}=\{1,2, \ldots, \mathrm{T}\}$ 
In total, Eq. 11 involves $n$ by $m$ and $t$ calculations. Thus, the final values used to extend the existing DER-CAM formulation in a seamless way are obtained by summation, where all binary variables except the selected $n, m$ pair are null for each time step $t$, as shown in Eq. 12:

$\eta_{e l, t}=\Sigma_{n} \Sigma_{m} \eta_{e l, n, m, t}$ for $\mathrm{t}=\{1,2, \ldots, \mathrm{T}\}$

While only the electric efficiency is mentioned, the corresponding fuel consumption, electricity output and, if relevant, heat generation are calculated in a similar fashion according to Eq. 10 and 11 using the same binary variables $\omega_{n, m, t}$.

While the use of binary variables for step-wise approximations of non-linear functions is not new, this technique has not been previously used in DER investment problems. It provides an effective way to increase the accuracy of DER modeling, but it must also be pointed out that this formulation carries the disadvantage only allowing single tabled values to be selected, with no interpolation between them. This decreases the precision of the results and for very restricted energy systems, such as buildings in islanded mode, there might be no feasible solution. Furthermore, the flexibility of the methodology is considerably reduced, as capacities have to be pre-defined in the data tables. Thus, if the user intends to investigate unit sizes outside of the table range, the relevant data has to be gathered prior to model application.

\subsection{Approach 2 - Linearization using SOS variables}

An alternative to the method using binary variables described above relies on the use of Special-Ordered-Set (SOS) variables, as proposed by [37]. SOS variables are defined as consecutive, ordered sets of variables. They differ from other variables in the sense that no more than one (called SOS1) or two (called SOS2) adjacent elements in the ordered set can take non-zero values.

By constraining their lower and upper boundaries to 0 and 1, SOS variables can be used as weighting factors in linearization methods, which is the approach used in this work to linearize the efficiency plane of distributed generation technologies. Unlike the binary approach described in the previous section, the use of SOS variables as weighting factors allows selecting either single tabled values or interpolating between two pre-defined operational load levels.

Although the direct use of binary variables is avoided, using SOS requires a MILP solver capable of dealing with this special type of variables. This is due to the fact that the SOS restrictions, forcing a maximum of one or two non-zero adjacent values, are modeled internally by the solver with auxiliary sets of binary variables [28], [38]. In this work, the CPLEX solver was used, which can automatically detect SOS structures in problem formulations, even if not explicitly declared, and adapt the branch-and-bound procedure accordingly [39].

Eq. 13 describes how the electrical efficiency, defined as a function of $P_{\text {inst }}$ and $U_{t}$, can be approximated in each time step $t$ using the SOS2 variables $x_{n, m, t}$ :

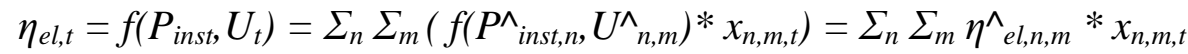

for $\mathrm{t}=\{1,2, \ldots, \mathrm{T}\}$ 
where the weighting variables $x_{n, m, t}$ are defined as positive variables with:

$0 \leq x_{n, m, t} \leq 1$ for $\mathrm{n}=\{1,2, \ldots, \mathrm{N}\}, \mathrm{m}=\{1,2, \ldots, \mathrm{M}\}$ and $\mathrm{t}=\{1,2, \ldots, \mathrm{T}\}$

As previously mentioned, solving the operational efficiency for DER technologies depends on the installed capacity and on the operational level in each time step. For this reason, a distinction must be made between the two, as the installed capacity is selected from the $N$ discrete capacity options and the operational level can be a continuous value interpolated between two consecutive $M$ levels. Thus, a SOS1 condition is used to solve the installed capacity and a SOS2 condition is used to find the operational load level, as illustrated in Fig. 6.

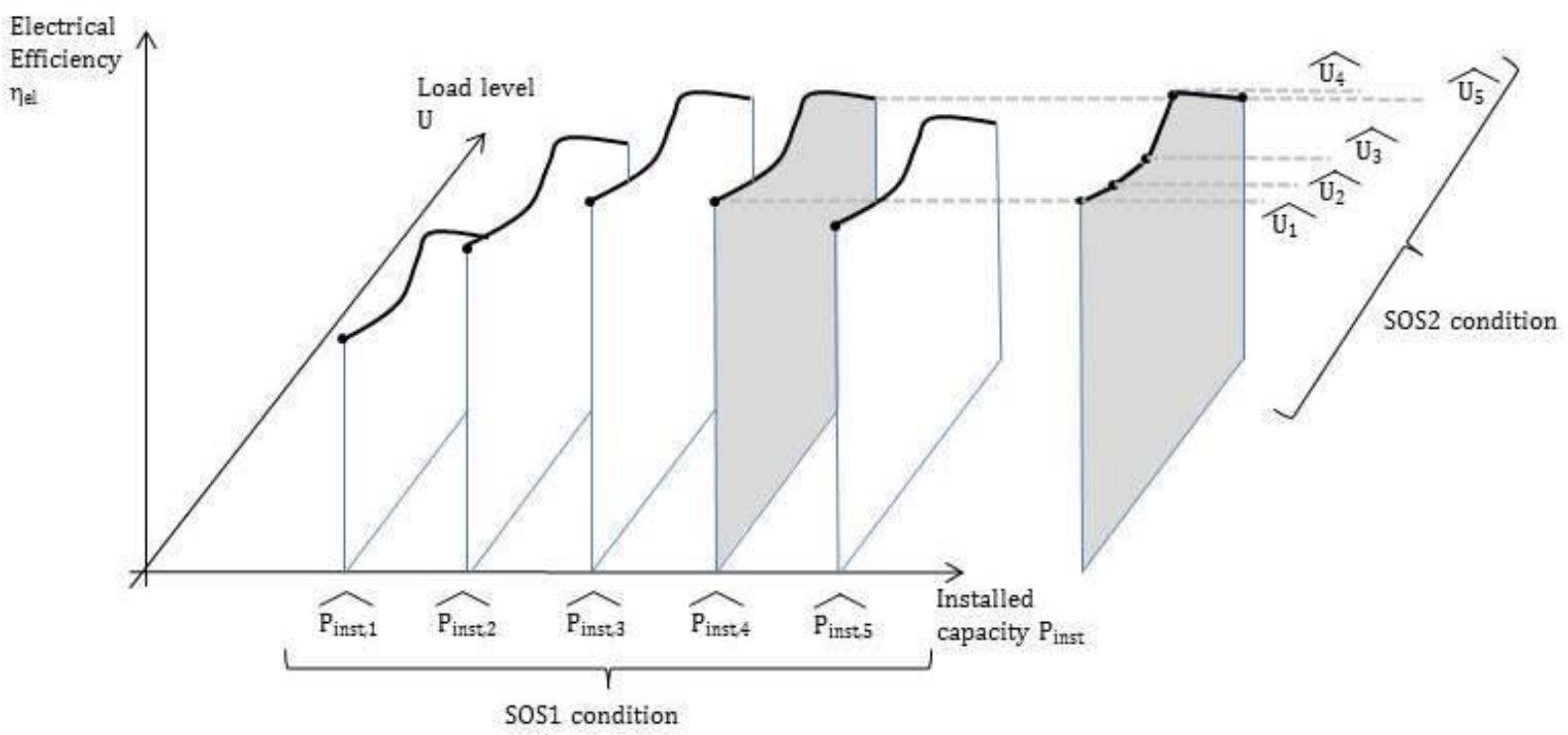

Fig.6. Schematic of the approach based on SOS variable declarations to choose efficiencies changing with installed capacity $P_{\text {inst }}$ and operational load level $U_{t}$ at each time step $t$

In this figure, the selection of the installed capacity from the discrete set is represented by the different "slices" for each tabled capacity. Once a capacity is chosen (in Fig. 6 this would be the installed capacity $P^{\wedge}$ inst, 4 highlighted in grey), the load level can be determined over time. In practice, the goal is to allow load levels to be any continuous number between a minimum part-load threshold and 1, representing the load operation range allowed for each technology.

In the tabled values, each $U_{t}$ level stands for a discrete point within the available operational load range and the use of SOS variables allows a better representation by creating the possibility of interpolating between two consecutive tabled load levels. E.g., if load levels are tabled with a resolution of $10 \%$, the relevant efficiency for $75 \%$ load operation could be obtained by interpolating between the values pre-defined for $70 \%$ and $80 \%$ load. This is done using variables $x_{n, m, t}$ under an SOS2 constraint in the $m$-dimension:

$\Sigma_{m} x_{n, m, t}=1$ and $x_{n, m, t}+x_{n, m-1, t} \geq 0$ for up to two elements (SOS2)

As stated above, no more than two consecutive elements within the SOS2 are allowed to be non-zero. Since the sum of all $x_{n, m, t}$ in the $n$ - and $m$-dimension has to be 1 , single tabled values can be chosen (if $x_{n, m, t}=1$ ) or interpolated between them (two consecutive $x_{n, m, t}$ values add up to 1 in the $m$-dimension). 
As stated above, the selection of a discrete capacity $P_{\text {inst }}$ requires the use of a SOS1 condition in the $n$-dimension. However, the GAMS platform used to implement DER-CAM does not support this directly: Only the last index can be assigned to an SOS variable. Therefore, an auxiliary binary variable $y_{n}$ is introduced to allow only one variable to be non-zero in the $n$ dimension of $x_{n, m, t}$ by applying Eq. 16 and 17:

$\sum_{m} x_{n, m, t}=y_{n}$ for $\mathrm{n}=\{1,2, \ldots, \mathrm{N}\}$ and $\mathrm{t}=\{1,2, \ldots, \mathrm{T}\}$

$\Sigma_{n} y_{n}=1$

The same method can be used to exclude load levels between the minimum threshold and zero. By assigning a binary variable to this range, only zero or the minimum load can be achieved. Also, since the sum of all $x_{n, m . t}$ values has to be 1 , it is important to always define "placeholders" with a zero load and a zero capacity, in case the unit is not installed and/or not operated at a certain point in time.

Similarly to the binary variable technique, $x_{n, m, t}$ is also used as a pointing variable when using SOS variables to indicate the chosen or interpolated tabled values for the electricity generation, fuel consumption and heat output. Eq. 18 shows the calculation of the supplied electricity at time step $t$ as an example:

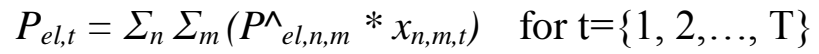

It should be noted that all these equations have to be solved for each time-step $t$, expressed in all variables. The installed capacity, which remains constant over time, is given by Eq. 19:

$P_{\text {inst }}=\Sigma_{n} \Sigma_{m}\left(P^{\wedge}{ }_{\text {inst }, n} * x_{n, m, t}\right)$ for $\mathrm{t}=\{1,2, \ldots, \mathrm{T}\}$

The main advantage of this approach is the flexibility in using the tabled values. Interpolation is allowed between different load levels, and further constraints such as a minimum load can be easily implemented. Thus, the results obtained using this approach should be more precise than using Approach 1. Furthermore, solvers such as CPLEX apply adapted branch-andbound procedures for SOS variables, which can have positive influence on the calculation time [38]. On the downside, more variables are required for this approach, such as the SOS1 variable $y_{n}$. This in return increases the complexity of the problem, and therefore, the overall processing time may become longer even considering the improved performance in SOSenabled solvers. It further should be noted that not all MILP solvers can handle SOS variables, and that their internal definition might even differ from solver to solver [40]. It is therefore advised to consult the respective solver manual before applying this approach. Additionally, the general drawbacks mentioned in the binary approach concerning the overall flexibility of the methodology also apply: Both approaches result in considerably less flexible models and require more user intervention.

The following chapters describe the integration of both approaches into DER-CAM and a comparison is conducted based on several case studies. 


\section{Modelling effects of considering variable efficiencies}

In order to evaluate the effects of variable efficiencies on energy system models and to be able to compare these approaches, they both have been integrated into DER-CAM and applied for several case studies. In the following sections the implementation of both approaches into DER-CAM, relevant input data and assumptions, as well as the results of various simulations are presented. The chapter concludes with a discussion of the observations.

\subsection{Implementation into DER-CAM}

The problem solved by DER-CAM is formulated using GAMS, which is commonly used for large scale modeling applications. It allows creating high level mathematical formulations and converts them to representations required by specific third-party solvers such as CPLEX, MINOS, or BARON. It can be used to model and solve various mathematical programs including linear (LP), non-linear (NLP), mixed integer linear (MILP) and mixed integer nonlinear programs (MINLP) [41]. Both the binary and SOS variables approaches described in this paper are directly supported by GAMS, although SOS variables are a special feature and not all MIP solvers available through GAMS support them.

Both the binary and SOS variable approaches were implemented in the latest Investment \& Planning (I\&P) version of DER-CAM (v4.1.1), which considers advanced features including investments in passive building components, such as windows and insulation.

As stated in Chapter 2, I\&P DER-CAM finds optimal solutions for microgrid and building energy supply systems, considering investments in energy supply and storage technologies, and this is done by sampling three typical days for each month or a typical year, resulting in a total of 36 days of hourly loads. Along with investment decisions, all energy outputs, fuel consumption, $\mathrm{CO}_{2}$ emissions, and other operating schedules are determined by DER-CAM and reported for this reference year.

Due to the current structure of DER-CAM, both approaches presented to model non-linear efficiency curves have to be adapted to ensure their implementation and several precalculations have to be made. Fig. 7 shows an overview of how both approaches are integrated and the corresponding data handling. Specifically, the user specifies efficiencies for certain partial loads and installed capacity sizes for each technology and relevant fuel type (light shaded on the left upper corner of the graphic). This data is highly relevant since the efficiency characteristics can differ significantly depending on the fuel used, even for the same technology. In this work, three efficiency tables were specified for the ICE, MT and FC, all three assuming natural gas operation. 


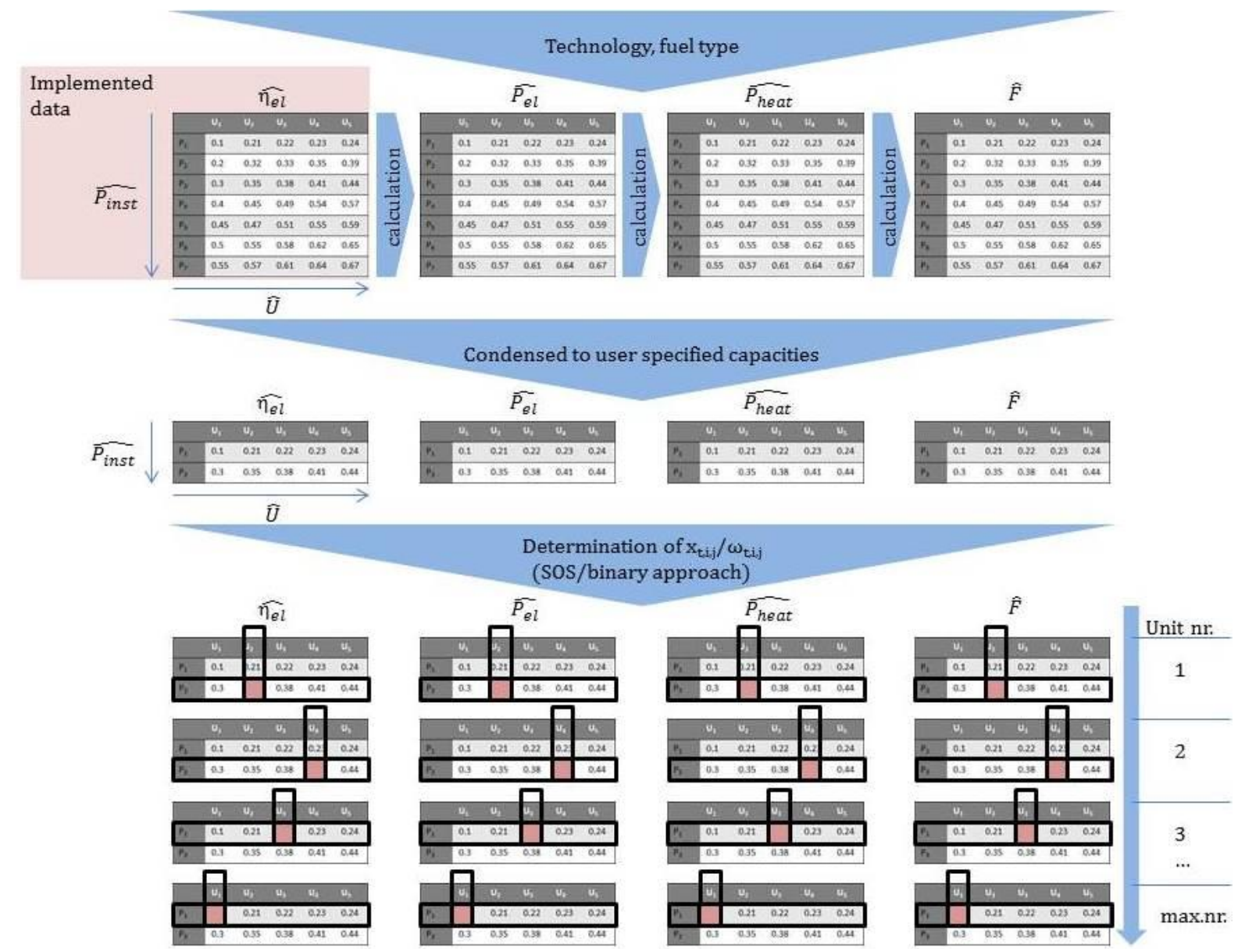

Fig. 7. Schematic of the implementation of the approach using SOS and binary variables in DER-CAM

Given the specified efficiency table for each size and load level, DER-CAM calculates the corresponding values for electricity output, fuel consumption and, if relevant, heat output. As part of the DER-CAM structure, users specify desired sizes of each technology in another part of the model. Consequently, the efficiency table is in a first step condensed to these sizes to avoid unnecessary calculations. When all data is pre-processed the actual optimization process is launched. The binary or SOS weighting variables are determined for each technology and calculation step $t$, determining the load levels for all points in time. As mentioned earlier, the variables are used to obtain values for all four data tables, marked in the figure with black boxes for the chosen index of $P_{\text {inst }}$ and $U_{t}$. The light shaded box indicates the resulting value in the table.

In addition to the above description, the structure of DER-CAM considers another dimension: the number of units, $k$, since the model allows for more than one unit of each size and technology to be installed, and determines the optimal number $k$ for each technology as part of the solution. This additional dimension requires that a maximum number of components are implemented in the model, and in this work 15 units have been set as a limit for each technology. DER-CAM applies the presented approaches for each unit up to the maximum number, determining if the unit should be installed and operated at a certain time $t$ or not. This is indicated in Fig. 7 on the lower right part. As an example, the equation for the electricity output of the approach using SOS2 variables is adapted in Eq. 20 by adding another index $k$ to the weighting variable referring to the number of installed units. 


$$
P_{e l, t, k}=\Sigma_{n} \Sigma_{m}\left(P^{\wedge} e_{l, n, m} * x_{n, m, t, k}\right) \text { for } \mathrm{t}=\{1,2, \ldots \mathrm{T}\} \text { and } \mathrm{k}=\{1,2, \ldots, \mathrm{K}\}
$$

The other equations for both approaches are adapted accordingly, adding the indices $t$ and $k$.

\subsection{Input data and assumptions}

As stated above, DER-CAM decides on the optimal energy supply system configuration using several input data for one reference year. The main inputs are [42]:

- hourly building loads for electricity, heating, cooling, domestic hot water and cooking

- natural gas and electricity prices

- local solar radiation

- $\mathrm{CO}_{2}$ emission factors for utilities to evaluate $\mathrm{CO}_{2}$ mitigation by local energy supply

- performance and cost data of building equipment including energy supply technologies

Additionally, as mentioned in chapter 4, the approaches now introduced require user specifications on the efficiency curves of each technology and applied fuel. Other parameters, such as electricity generation and fuel consumption, are calculated based on these efficiencies. The heat output is determined based on the assumption that the overall efficiency of all three technologies considered in this paper is constant for all load levels. This simplification is reasonable, as less efficiency part load operation levels lead to higher waste heat. When this happens the heat to power ratio increases (greater amount of heat recovered and lower power output), which is compatible with a constant overall efficiency, as illustrated in Eq. 21. This equation shows how the heat output table is determined for both approaches based on Eq. 4 and 5 and a constant overall efficiency for each capacity:

$P^{\wedge}{ }_{\text {heat }, n, m}=\left(\left(\eta_{\text {overall }, n}-\eta^{\wedge}{ }_{e l, n, m}\right) / \eta^{\wedge}{ }_{e l, n, m}\right) * P^{\wedge}{ }_{e l, n, m}$

for $n=\{1,2, \ldots, N\}, m=\{1,2, \ldots, M\}, t=\{1,2, \ldots T\}, k=\{1,2, \ldots, K\}$

This method for calculating CHP efficiency, known simply as total system efficiency, is the most commonly used approach and an adequate method to compare CHP efficiency to the efficiency of a system with separate heat and power production. In situations where the electrical efficiency of CHP is being compared with conventional power production, the alternative effective electric efficiency metric should be used. As DER-CAM considers simultaneously different end-use loads including both power and heating, and different options to meet these loads are present in the model, the total system efficiency method is better suited.

The improvements made on DER-CAM to model non-linear efficiency curves were analysed by performing a case study with a number of selected buildings, which have been previously analysed using DER-CAM in the report "Encouraging Combined Heat and Power in California Buildings" [42]. The results from this report were used as a reference for comparison when evaluating the effects of considering variable efficiencies.

According to [42], building load profiles were obtained from the California Commercial EndUse Survey [43] for four building types in the city of San Francisco. The facilities investigated are a large lodging (LLODG), a large office building (LLOFF), a medium-sized office building (MLOFF) and a large warehouse (LWRHS). In the reference report several run sets with different objectives and frame conditions have been performed [42]. In this 
paper, test runs " $4 \mathrm{e} 10$ " from the report have been chosen, where the objective function was to minimize overall building $\mathrm{CO}_{2}$ emissions considering a maximum global payback time of 10 years for DER investments. Thus, equation 2 as described earlier in this paper is applied as the objective function.

Key results obtained in this run suggested the installation of Fuel Cell Systems with a Heat Exchanger (FC-HX) and Micro-turbines with a Heat Exchanger (MT-HX) as the $\mathrm{CO}_{2}$ optimal solution. Their technical specifications together with the relevant cost data are listed in Table 3 and are taken from [42].

Table 3. Technical specifications of investigated CHP technologies [42]

\begin{tabular}{l|rrrrrr}
\hline Technology & $\begin{array}{c}\text { Electrical } \\
\text { capacity } \\
{[\mathrm{kW}]}\end{array}$ & $\begin{array}{c}\text { Lifetime } \\
\text { [Years] }\end{array}$ & $\begin{array}{c}\text { Capital } \\
\text { cost } \\
{[\$ / \mathrm{kW}]}\end{array}$ & $\begin{array}{c}\text { Maintenance } \\
\text { cost }[\$ / \mathrm{kWh}]\end{array}$ & $\begin{array}{c}\text { Full load } \\
\text { e electric } \\
\text { efficiency } \\
{[\%]}\end{array}$ & $\begin{array}{c}\text { Heat-to- } \\
\text { Power } \\
\text { ratio } \alpha \\
{[-]}\end{array}$ \\
\hline MT-HX & 60 & 10 & 1,584 & 0.017 & 31 & 1.8 \\
MT-HX & 150 & 10 & 1,290 & 0.017 & 33 & 1.4 \\
FC-HX & 100 & 10 & 4,192 & 0.033 & 60 & 0.53 \\
FC-HX & 250 & 10 & 3,359 & 0.033 & 60 & 0.53 \\
\hline
\end{tabular}

MT: micro-turbine, FC: fuel cell, HX: heat exchanger for waste heat utilization

Part load efficiency data for natural gas powered MT and FC was taken from reports [44] and [45]. All data was slightly scaled to match the full load electrical efficiencies already specified in DER-CAM as indicated in Table 3. Table 4 defines the part load performance for two capacities of a natural gas powered micro-turbine, which are considered in the model. Analysing the data on this table it can be concluded that the maximum efficiency for the large $150 \mathrm{~kW}$ micro-turbine at full load is slightly higher than for the smaller $60 \mathrm{~kW}$ unit. The implemented minimum load for the fuel cell is $30 \%$ and for the micro-turbine $10 \%$.

Table 4. Electrical efficiencies of natural gas powered MT [44]

\begin{tabular}{ll|lllllllll}
\hline & \multicolumn{10}{|c}{ Load level } \\
\cline { 2 - 11 } Installed capacity & $\mathrm{U}_{1, \mathrm{t}}$ & $\mathrm{U}_{2, \mathrm{t}}$ & $\mathrm{U}_{3, \mathrm{t}}$ & $\mathrm{U}_{4, \mathrm{t}}$ & $\mathrm{U}_{5, \mathrm{t}}$ & $\mathrm{U}_{6, \mathrm{t}}$ & $\mathrm{U}_{7, \mathrm{t}}$ & $\mathrm{U}_{8, \mathrm{t}}$ & $\mathrm{U}_{9, \mathrm{t}}$ \\
& $0 \%$ & $30 \%$ & $40 \%$ & $50 \%$ & $60 \%$ & $70 \%$ & $80 \%$ & $90 \%$ & $100 \%$ \\
\hline $\mathrm{P}_{1}$ & $60 \mathrm{~kW}$ & 0 & 0.227 & 0.251 & 0.264 & 0.277 & 0.29 & 0.3 & 0.306 & 0.31 \\
$\mathrm{P}_{2}$ & $150 \mathrm{~kW}$ & 0 & 0.241 & 0.268 & 0.281 & 0.295 & 0.31 & 0.32 & 0.326 & 0.33 \\
\hline
\end{tabular}

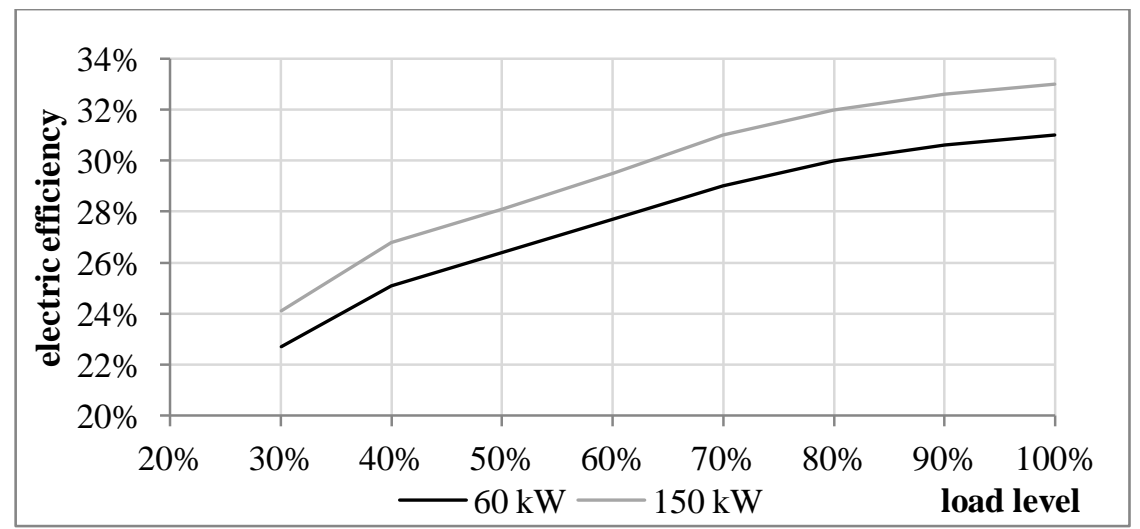

Fig. 8. Electrical efficiencies for natural gas powered Micro Turbines 
Table 5 indicates the part load efficiencies for both Fuel Cell capacities considered in this work. According to [42], maximal efficiency for both unit sizes is considered equal. The tabled values reveal that the slope of the performance curve is close or even equal to zero in the range of load levels between $60 \%$ and $100 \%$.

Table 5. Electrical efficiencies of natural gas powered Phosphoric Acid FC [45]

\begin{tabular}{ll|lllllllll}
\hline & \multicolumn{10}{c}{ Load level } \\
\cline { 2 - 10 } Installed capacity & $\mathrm{U}_{1, \mathrm{t}}$ & $\mathrm{U}_{2, \mathrm{t}}$ & $\mathrm{U}_{3, \mathrm{t}}$ & $\mathrm{U}_{4, \mathrm{t}}$ & $\mathrm{U}_{5, \mathrm{t}}$ & $\mathrm{U}_{6, \mathrm{t}}$ & $\mathrm{U}_{7, \mathrm{t}}$ & $\mathrm{U}_{8, \mathrm{t}}$ & $\mathrm{U}_{9, \mathrm{t}}$ \\
& $0 \%$ & $30 \%$ & $40 \%$ & $50 \%$ & $60 \%$ & $70 \%$ & $80 \%$ & $90 \%$ & $100 \%$ \\
\hline $\mathrm{P}_{1}$ & $100 \mathrm{~kW}$ & 0 & 0.35 & 0.379 & 0.391 & 0.399 & 0.401 & 0.401 & 0.401 & 0.4 \\
$\mathrm{P}_{2}$ & $250 \mathrm{~kW}$ & 0 & 0.35 & 0.379 & 0.391 & 0.399 & 0.401 & 0.401 & 0.401 & 0.4 \\
\hline
\end{tabular}

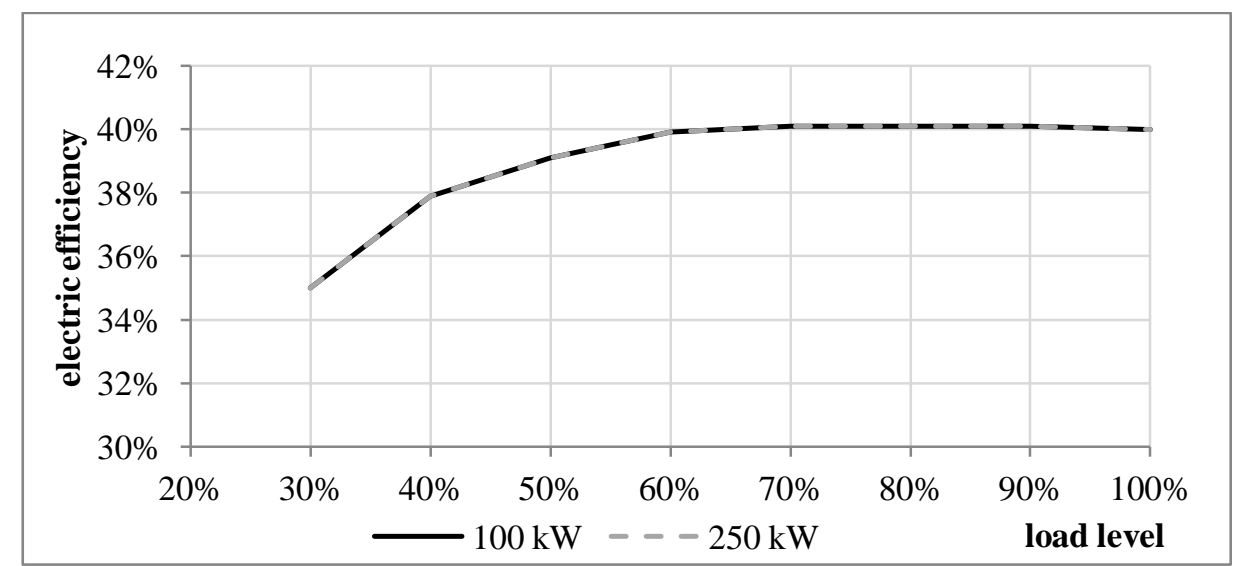

Fig. 9. Electrical efficiencies for natural gas powered Phosphoric Acid FC

In the standard version of DER-CAM, minimum load levels were implemented to limit the impacts of the simplification involving constant efficiencies. This resulted in a rather conservative minimum load level of $90 \%$ for the fuel cell, which was lowered to a minimum operational load level of $30 \%$ in this work, as a result of considering variable efficiencies.

Based on the input data presented, four different optimization runs were performed for each of the two methods described to incorporate non-linear efficiency curves. Additionally, the four reference cases with fixed efficiencies have been reproduced with the latest v4.1.1 DER-CAM code for the purpose of model validation and solver performance comparison between all approaches. Thus, a total number of 12 optimization runs have been carried out.

In the following subchapter the obtained results are presented and discussed in detail.

\subsection{Optimization results}

Four buildings in the city of San Francisco have been investigated, as indicated earlier. Fig. 10 depicts the aggregated capacities suggested by DER-CAM when considering the $\mathrm{CO}_{2}$ minimization objective function in all four cases. The results are shown separately for each of the approaches implemented and the results obtained with fixed efficiencies are referred to as "original", representing the base case. The results obtained using binary and SOS2 variables 
to approximate non-linear efficiencies are named correspondingly. Please note that the sizes for all technologies refer to electrical capacities, except for the heat storage.

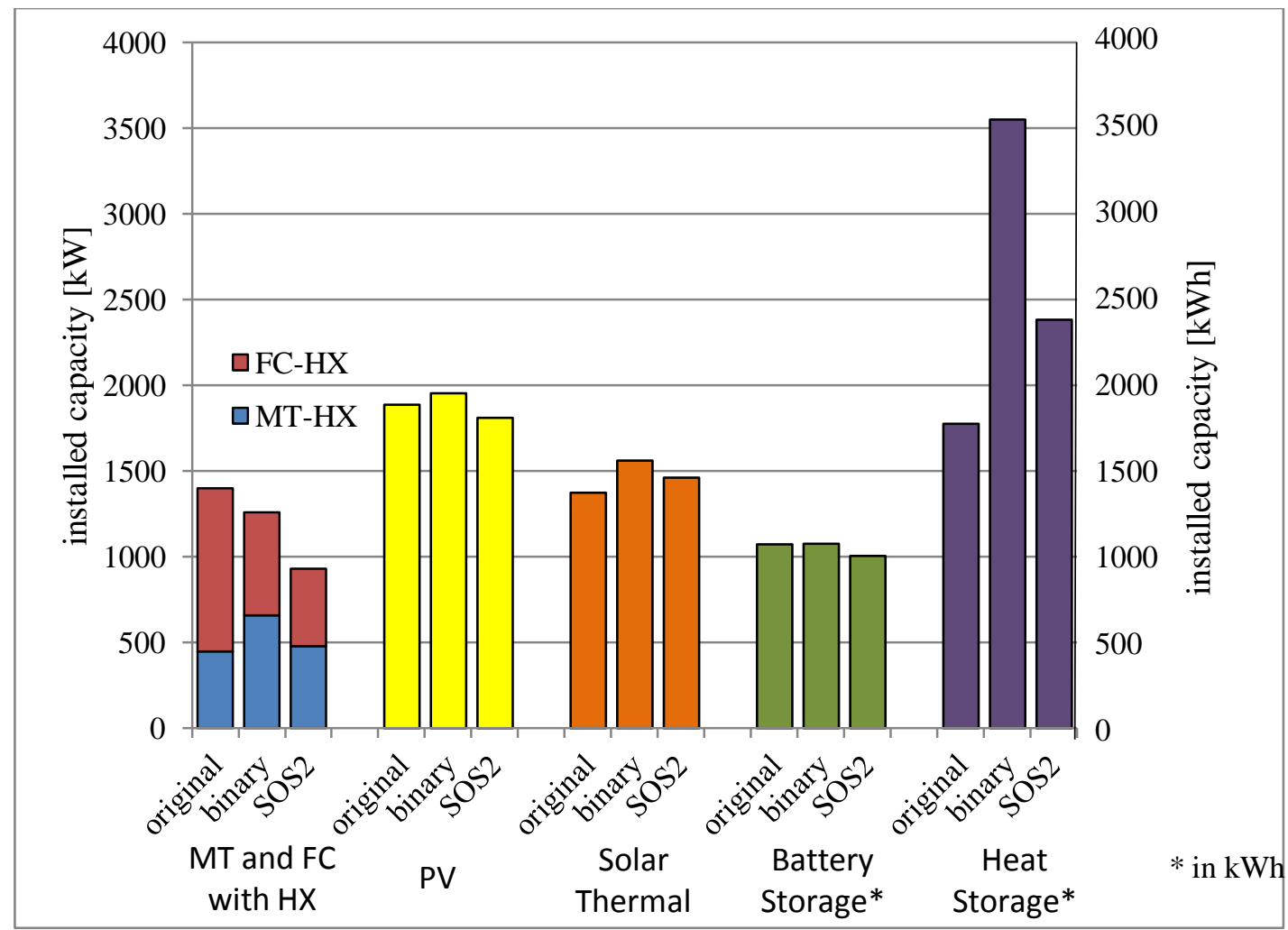

Fig. 10. Accumulated optimal unit capacities for the four investigated buildings

Results shown in Fig. 10 indicate that the CHP (MT and FC with HX) capacities obtained using the binary approach and the benchmark constant efficiency methods differ only slightly. A larger deviation can be observed when using SOS2 variables to model variable efficiencies. Despite these differences, the ratio between installed fuel cells and micro-turbines is almost constant for both proposed methods. In all buildings and methods used, discrete-sized generation technologies selected by DER-CAM were equipped with heat exchangers to allow CHP operation. Besides MT and FC, PV modules and solar thermal collectors were also part of the solutions found in all cases.

It can also be observed that the capacity of DER technologies found by DER-CAM is only slightly affected by the consideration of variable efficiencies. Fluctuations between the approaches for PV and ST installations are only minor. Changes for the battery storage capacities are negligible. The largest observed impact occurred on heat storage, where the use of the binary approach led to optimal installed capacities nearly twice the size of those obtained in the base case.

The reasons for the observed differences can be explained when investigating the results in greater detail. Tables 6 and 7 lists detailed results for all cases.

Table 6. Detailed simulation results for the first two buildings and all three approaches

\begin{tabular}{l|ccc|ccc}
\hline Building case & \multicolumn{3}{|c|}{$L L O D G$} & \multicolumn{3}{c}{ LLOFF } \\
\hline Approach & Original & Binary & SOS2 & Original & Binary & SOS2 \\
\hline \multicolumn{5}{c}{$\mathrm{CO}_{2}$ emissions } \\
\hline Total Annual $\mathrm{CO}_{2}$ & 1.805 .483 & 1.758 .140 & 2.122 .843 & 3.548 .091 & 3.560 .468 & 3.529 .838 \\
\hline
\end{tabular}




\begin{tabular}{|c|c|c|c|c|c|c|}
\hline \multicolumn{7}{|l|}{$\overline{\text { emissions [kg] }}$} \\
\hline \multicolumn{7}{|c|}{ Costs } \\
\hline $\begin{array}{l}\text { Total Annual Energy } \\
\text { Costs }[\$]\end{array}$ & 697,702 & 707,919 & 761,750 & $1,113,650$ & $1,117,604$ & $1,117,581$ \\
\hline \multicolumn{7}{|c|}{ Installed Capacities } \\
\hline$\overline{\mathrm{FC}-\mathrm{HX}[\mathrm{kW}]}$ & 600 & 500 & 0 & 0 & 0 & 0 \\
\hline MT-HX [kW] & 60 & 60 & 180 & 330 & 390 & 300 \\
\hline CHP total $[\mathrm{kW}]$ & 660 & 560 & 180 & 330 & 390 & 300 \\
\hline $\mathrm{PV}[\mathrm{kW}]$ & 205 & 222 & 227 & 686 & 661 & 651 \\
\hline Solar Thermal [kW] & 1,238 & 1,355 & 1,331 & 0 & 0 & 0 \\
\hline Battery Storage $[\mathrm{kWh}]$ & 0 & 233 & 0 & 0 & 0 & 0 \\
\hline Heat Storage $[\mathrm{kWh}]$ & 1,776 & 2,527 & 1,920 & 0 & 490 & 463 \\
\hline \multicolumn{7}{|c|}{ Energy Generation } \\
\hline $\begin{array}{l}\text { CHP Electricity } \\
\text { Generation }[\mathrm{kWh}]\end{array}$ & $4,998,619$ & $4,314,180$ & $1,021,172$ & $1,901,746$ & $2,217,300$ & $1,901,035$ \\
\hline $\begin{array}{l}\text { CHP Heat Generation } \\
{[\mathrm{kWh}]}\end{array}$ & $2,630,717$ & $2,418,665$ & $1,838,646$ & $2,999,596$ & $3,429,561$ & $3,296,313$ \\
\hline $\begin{array}{l}\text { CHP fuel consumption } \\
{[\mathrm{kWh}]}\end{array}$ & $8,428,554$ & $7,326,588$ & $3,294,721$ & $6,020,685$ & $7,045,543$ & $6,141,124$ \\
\hline \multicolumn{7}{|c|}{ Model Performance and Key Data } \\
\hline CPU time $[\mathrm{s}]$ & 129 & 23,383 & 189,321 & 158 & 23,368 & 145,287 \\
\hline Variables [-] & 523,307 & $1,791,659$ & $2,102,699$ & 523,307 & $1,791,659$ & $2,102,699$ \\
\hline Equations [-] & 293,353 & 441,961 & 753,001 & 293,353 & 441,961 & 753,001 \\
\hline
\end{tabular}


Table 7. Detailed simulation results for the last two buildings and all three approaches

\begin{tabular}{|c|c|c|c|c|c|c|}
\hline \multirow{2}{*}{$\begin{array}{l}\text { Building case } \\
\text { Approach }\end{array}$} & \multicolumn{3}{|c|}{$M L O F F$} & \multicolumn{3}{|c|}{ LWRHS } \\
\hline & Original & Binary & SOS2 & Original & Binary & SOS2 \\
\hline \multicolumn{7}{|c|}{$\mathrm{CO}_{2}$ emissions } \\
\hline $\begin{array}{l}\text { Total Annual } \mathrm{CO}_{2} \\
\text { emissions [kg] }\end{array}$ & 891.974 & 196.201 & 877.663 & Missing & Missing & 171.302 \\
\hline \multicolumn{7}{|c|}{ Costs } \\
\hline $\begin{array}{l}\text { Total Annual Energy } \\
\text { Costs [\$] }\end{array}$ & 484,024 & 503,673 & 484,138 & 131,046 & 122,984 & 121,266 \\
\hline \multicolumn{7}{|c|}{ Installed Capacities } \\
\hline C-HX & 250 & 0 & 350 & 100 & 100 & 100 \\
\hline MT-HX & 60 & 210 & 0 & 0 & 0 & 0 \\
\hline CHP total $[\mathrm{kW}]$ & 310 & 210 & 350 & 100 & 100 & 100 \\
\hline$P V[k W]$ & 823 & 872 & 731 & 173 & 198 & 201 \\
\hline Solar Thermal [kW] & 133 & 206 & 131 & 3 & 1 & 0 \\
\hline Battery S & 502 & 471 & 686 & 571 & 372 & 319 \\
\hline Heat Storage $[\mathrm{kWh}]$ & 0 & 534 & 0 & 0 & 0 & 0 \\
\hline \multicolumn{7}{|c|}{ Energy Generation } \\
\hline $\begin{array}{l}\text { CHP Elec } \\
\text { Generatio }\end{array}$ & $1,873,291$ & 763,392 & $2,520,372$ & 574,120 & 520,960 & 523,450 \\
\hline $\begin{array}{l}\text { CHP Heat Generation } \\
{[\mathrm{kWh}]}\end{array}$ & $1,103,721$ & $1,130,125$ & $1,338,894$ & 51,738 & 51,794 & 51,940 \\
\hline $\begin{array}{l}\text { CHP fuel consumption } \\
\text { [kWh] }\end{array}$ & $3,394,010$ & $2,372,110$ & $4,211,090$ & 956,867 & 867,984 & 873,318 \\
\hline \multicolumn{7}{|c|}{ Model Performance and Key Data } \\
\hline CPU time $[\mathrm{s}]$ & 2,426 & 23,536 & 163,740 & 21,393 & 84,334 & 77,479 \\
\hline Variables [-] & 523,307 & $1,791,659$ & $2,102,699$ & 523,307 & $1,791,659$ & $2,102,699$ \\
\hline Equations [-] & 293,353 & 441,961 & 753,001 & 293,353 & 441,961 & 753,001 \\
\hline
\end{tabular}

When investigating the total annual energy costs listed on the top of Tables 6 and 7, it is observed that these are barely affected by considering flexible efficiencies. The used solver precision was five percent for which reason deviations in the optimal result lower or equal than this value are in the precision range and do not necessarily reflect changes induced by the approaches applying variable efficiencies. The largest deviation can be found for the LLODG building when using the SOS2 based approach. Otherwise, the changes of total costs are close to zero. Likewise, as already concluded from the figure above, the average of installed capacities does not deviate largely from the reference scenario. Solely the size of the CHP units for the LLODG building is dramatically lower for the approach using SOS2 variables.

Concerning storage technologies, a large increase can be observed for the hot water tank, as stated earlier. This is mainly due to a greater ability to generate heat, as the heat-to-power ratio increases during part load operation. This is a direct consequence of considering variable efficiencies, as lower electric efficiencies result in a higher ability to recover heat when compared to the original case where the heat-to-power ratio is assumed to be constant. Another reason for the increased importance of heat storage is the change in technology investment. Tables 6 and 7 indicate that MT are more favorable in the adapted approaches while FC capacities decrease. Thus, due to the very different heat-to-power ratios of the MT and FC, the overall ratio between heat and electricity changes significantly from one case to 
the other. Namely, the applied micro-turbine has a much larger heat-to-power ratio than the considered FC system, which increases heat generation considerably compared to the reference scenarios. These characteristics are also the reason for a strong decline in the electricity generation for the MLOFF building with the applied binary approach, despite a slight increase in heat supply. Despite the minor changes in total heat supply, the large increase in heat storage might be a consequence of the considerable larger amounts of supplied heat per hour, which might exceed hourly consumption of the building and therefore require larger storage. Thus, it can be concluded that two factors have an impact on the heat supply rates and consequently heat storage size:

1) Changes in the part load heat-to-power ratio and

2) Changes in the overall heat-to-power ratio of the system due to different technology capacities.

As stated earlier, overall investment costs are hardly affected by including variable efficiencies in the optimization process. However, operational performance of all relevant technologies is different, which would suggest different system costs. Thus, the results indicate that changes in the technology mix, in this case towards larger microturbine installations, compensate for variations observed in operational performance. .

In the last part of both above tables key data for the optimization models is listed. The required CPU time increased for all the cases considerably. The largest changes can be observed for the approach using SOS2 variables, which had longer running times up to the factor $10^{6}$. The binary approach solved generally faster than the SOS2 alternative. However, it was still considerably slower than the reference cases with run time increases in the range of $10^{2}$ to $10^{4}$. As a conclusion, it can be stated that both approaches cause considerably longer calculation times with the SOS2 approach having the largest increase.

\subsection{Modelling with variable vs. non-variable efficiencies}

As discussed in the previous section, both modelling approaches only have limited impacts on the objective function. However, calculation time and complexity of the model increase considerably. Therefore, it is crucial for researchers and system designers to evaluate the impacts and consequently the need for the presented approaches before applying them in a specific building optimization. The efficiency data tables presented earlier (Table 2, 4 and 5) indicated that deviations from the original approach only occur in part loads, for which full load efficiency cannot be achieved. Fig. 11 depicts the share of the total accumulated amount of hours of operation of installed units for all four investigated buildings distinguished by the corresponding load levels. 


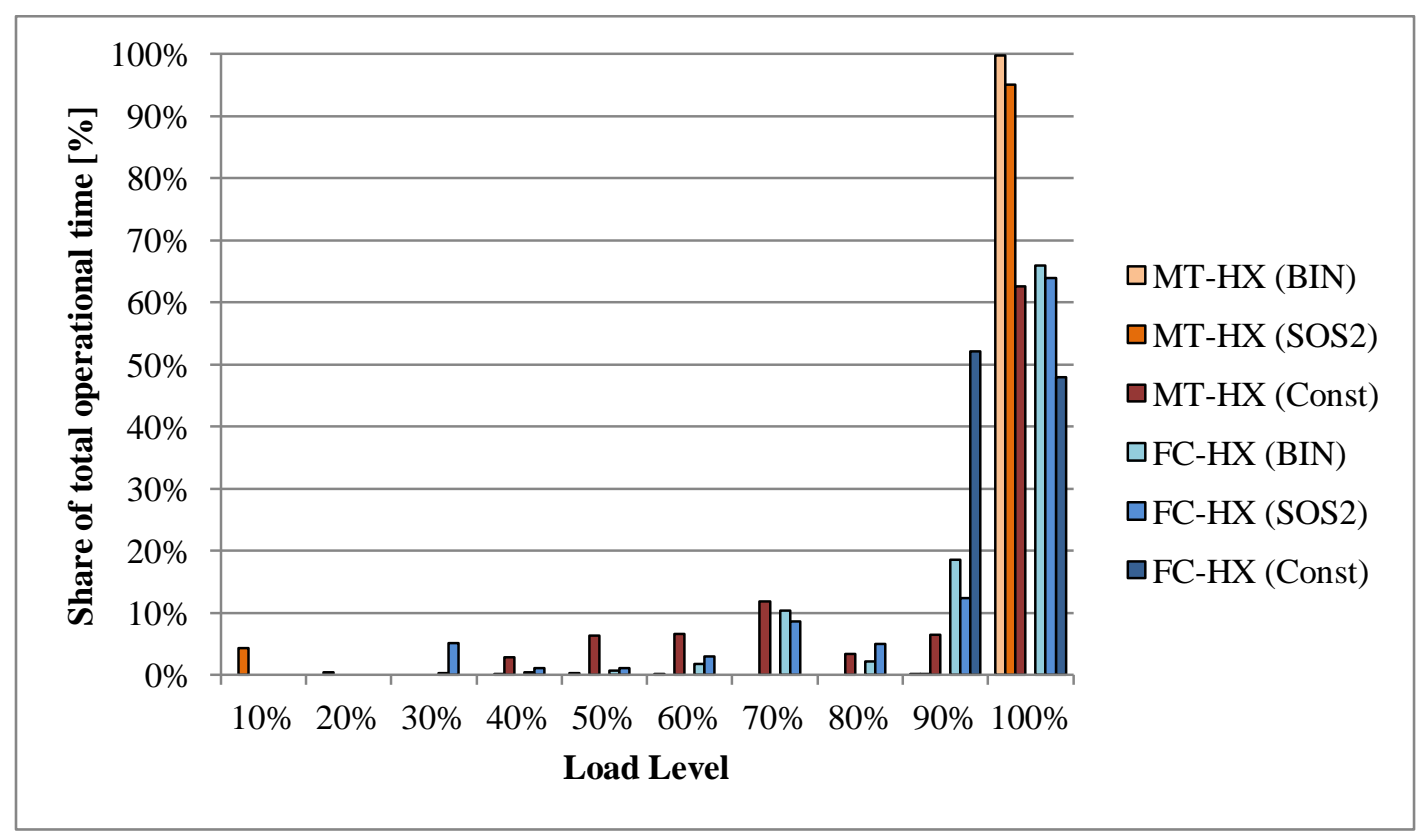

Fig. 11. Accumulated hours of operation for all buildings at relevant load levels compared by applied modelling approach

This figure indicates that the units were mostly used in full load operation for both approaches. Further, distinction between the fuel cell and the micro-turbine modelling is visible. The micro-turbine is almost exclusively used at full capacity. Fuel cell part load operation, however, seems to be more relevant. At load levels $30 \%, 70 \%$ and $90 \%$ the fuel cell is operated a considerable amount of time. Altogether, the FC units are modelled $48 \%$ and $44 \%$ of the operational time in part load using the binary and the SOS2 approach, respectively. This observation is important considering the fact that part load operation of fuel cells is limited to a minimal $90 \%$ in the original DER-CAM version considering constant efficiencies and for that reason fuel cell technology that cannot follow the load. It is also relevant to note that in DER-CAM the smallest available size for the MT is $60 \mathrm{~kW}$, which is lower than the minimum installed capacity of $100 \mathrm{~kW}$ for the fuel cell. Further, the largest available size is $250 \mathrm{~kW}$ for the fuel cell and only $150 \mathrm{~kW}$ for the micro-turbine. This is also influencing the load performance of the components, since smaller units are more likely to run in full load. Furthermore, it should be noted that in the original DER-CAM version the micro-turbine was often used in part load operation. Taking into account the fact that originally fuel cells are limited to a minimal $90 \%$ part load it is interesting to observe that the micro-turbine is used to a similar extent of what the fuel cells are used once the binary or SOS2 methods are implemented. However, a general statement cannot be made in this work, both because of the original imposed constrains in terms of minimal load and because consumption profiles also change for each building and the determined capacities consist for several cases of combinations of small and large units. Therefore, it is recommended to investigate in future studies, if the observation made in this work can be generalized or is only valid for these specific component sizes.

Given the results of this study, it can be stated that the effect of variable efficiencies seems to be technology dependent for the given configurations. Since the micro-turbine is modelled mainly in full load, the assumption of constant efficiencies is reasonable in DER-CAM. For fuel cell technologies, however, an approach with variable efficiencies might be relevant for certain cases and technologies (e.g. PEM fuel cells) given the fact that part load modelling accounts for up to $48 \%$ of the operational time. Including the observations of the previous 
section indicating no major change in overall system costs and a shift towards larger installed capacities of the MT, it can be argued that considering part load performance would lead to a cost increase compared to the reference case when assuming the same installation. However, this is prevented by changing the mix of technologies with more or larger micro turbine units operating most of the time in full load.

Concerning the performance of the adapted DER-CAM versions, the SOS2 approach caused the largest increase in calculation time. The advantage of using SOS2 variables is that they allow for interpolation between tabled load levels in the approach presented and thus might lead to more precise results. Table 8 indicates the number of interpolations actually applied in the optimal solutions for all four buildings dependent on the technology.

Table 8. Total number of interpolations applied in the SOS2 approach for all buildings

\begin{tabular}{l|cc}
\hline & $M T-H X$ & $F C-H X$ \\
\hline Number of interpolations & 100 & 279 \\
\hline
\end{tabular}

As expected, most of the interpolations have been made for fuel cell units, resulting from part load operation occurring in a significant amount of time. The micro-turbine operation required interpolation in a lower number of 100 hours, which represents a very low share of only $1.4 \%$. Thus, given the large increase in computational time and the sparse use of interpolation, the SOS2 approach does not seem favorable for the building range investigated in this work. Further, it should be mentioned that this approach results in a less flexible model, since SOS2 variables are not supported by all solvers and their definition is different between solvers. However, for small scale grid-isolated energy systems, the SOS2 approach could still be favorable, due to an increased importance of part load performance. The use of the binary approach might not be applicable for such specific cases, as it does not allow for interpolation, which could be required to meet the building energy demand supplied by only one or two components. Thus, it could lead to an infeasible problem.

\section{Conclusion and recommendations}

In this paper two approaches were presented to account for variable efficiencies when modelling CHP technologies in distributed energy systems. Furthermore, the optimization model DER-CAM was adapted to implement these features and case study optimizations have been successfully performed to compare both approaches and to evaluate the effect of taking variable efficiencies into account. The main findings are:

- The total annual energy costs are not subject to large changes, when considering variable efficiencies.

- However, changes in the choice of technologies were observed. FC units were replaced by MT and slightly also vice-versa. The overall installed capacities per building varied moderately with one extreme example.

- System performance was affected considerably. Storage technologies gained increased importance, with particular focus on heat storage.

- Further, it was found that in DER-CAM the importance of modelling variable efficiencies depends on the technology. The micro-turbine was modelled $97 \%$ of the time in full load, which corresponds to the original DER-CAM version with constant 
efficiencies. On the contrary, fuel cell units were referred to being operated half of the time in part load.

- Both approaches increased the calculation time considerably. The binary approach led to processing times being 2 to 100 times longer.

- The SOS2 approach caused the largest increases by factors up to $10^{6}$. Interpolations in load levels were hardly applied, being the main advantage of this approach.

- The results show that constant efficiencies can be reasonable to model CHP performance. Investment decisions were only slightly different when considering variable efficiencies. However, when identifying optimal operational strategies, the presented approaches can lead to recommendations that are more realistic.

Based on these conclusions, the following recommendations can be made:

- The implementation of variable efficiencies should not be generally applied due to the significant increase in computational time. An individual assessment beforehand in regard to the investigation purpose should be made.

- Results indicate that micro-turbines could be modelled with fixed efficiencies, although further research is suggested to assess if this observation can be generalized or if it is only valid for the given component sizes.

- Applying variable efficiencies for fuel cells should be considered and could be subject to further investigation with an increased number of buildings and locations.

- When modelling variable efficiencies, the binary approach should be used with processing times being considerably faster than for the SOS2 approach.

- The SOS2 approach could be used for very specific cases investigating small gridisolated systems, which require a large flexibility in part load operation.

- It is recommended to implement the binary approach also in the Operational version of DER-CAM, since unit performance is affected and storage solutions gain importance.

\section{Acknowledgement}

The Distributed Energy Resources Customer Adoption Model (DER-CAM) has been designed at Lawrence Berkeley National Laboratory (LBNL). DER-CAM has been funded partly by the Office of Electricity Delivery and Energy Reliability, Distributed Energy Program of the U.S. Department of Energy under Contract No. DE-AC02-05CH11231. 


\section{References}

[1] M. Bianchi, A. De Pascale, F. Melino, and A. Peretto, "Performance prediction of microCHP systems using simple virtual operating cycles," Applied Thermal Engineering, vol. 71, no. 2, pp. 771-779, Oct. 2014.

[2] M. Bianchi and A. De Pascale, "Emission Calculation Methodologies for CHP Plants," Energy Procedia, vol. 14, no. 0, pp. 1323-1330, 2012.

[3] B. Thomas, "Benchmark testing of Micro-CHP units," Applied Thermal Engineering, vol. 28, no. 16, pp. 2049-2054, Nov. 2008.

[4] M. Ebrahimi, A. Keshavarz, and A. Jamali, "Energy and exergy analyses of a microsteam CCHP cycle for a residential building," Energy and Buildings, vol. 45, pp. 202210, Feb. 2012.

[5] X. Q. Kong, R. Z. Wang, Y. Li, and X. H. Huang, "Optimal operation of a microcombined cooling, heating and power system driven by a gas engine," Energy Conversion and Management, vol. 50, no. 3, pp. 530-538, Mar. 2009.

[6] D. W. Wu and R. Z. Wang, "Combined cooling, heating and power: A review," Progress in Energy and Combustion Science, vol. 32, no. 5-6, pp. 459-495, Sep. 2006.

[7] G. Kayo, A. Hasan, and K. Siren, "Energy sharing and matching in different combinations of buildings, CHP capacities and operation strategy," Energy and Buildings, vol. 82, pp. 685-695, Oct. 2014.

[8] C. Milan, C. Bojesen, and M. P. Nielsen, "A cost optimization model for 100\% renewable residential energy supply systems," Energy, vol. 48, no. 1, pp. 118-127, Dec. 2012.

[9] M. Münster, P. E. Morthorst, H. V. Larsen, L. Bregnbæk, J. Werling, H. H. Lindboe, and H. Ravn, "The role of district heating in the future Danish energy system," Energy, vol. 48, no. 1, pp. 47-55, Dec. 2012.

[10] H. Lund, B. Möller, B. V. Mathiesen, and A. Dyrelund, "The role of district heating in future renewable energy systems," Energy, vol. 35, no. 3, pp. 1381-1390, Mar. 2010.

[11] P. Liu, E. N. Pistikopoulos, and Z. Li, "An energy systems engineering approach to the optimal design of energy systems in commercial buildings," Energy Policy, vol. 38, no. 8, pp. 4224-4231, Aug. 2010.

[12] H. Ren and W. Gao, "A MILP model for integrated plan and evaluation of distributed energy systems," Applied Energy, vol. 87, no. 3, pp. 1001-1014, Mar. 2010.

[13] A. D. Hawkes and M. A. Leach, "Modelling high level system design and unit commitment for a microgrid," Applied Energy, vol. 86, no. 7-8, pp. 1253-1265, Jul. 2009.

[14] E. Thorin, H. Brand, and C. Weber, "Long-term optimization of cogeneration systems in a competitive market environment," Applied Energy, vol. 81, no. 2, pp. 152-169, Jun. 2005.

[15] H. Cho, S. D. Eksioglu, R. Luck, and L. M. Chamra, "Operation of a cchp system using an optimal energy dispatch algorithm," in ASME 2008 2nd International Conference on Energy Sustainability collocated with the Heat Transfer, Fluids Engineering, and 3rd Energy Nanotechnology Conferences, 2008, pp. 747-754.

[16] H. Cho, P. J. Mago, R. Luck, and L. M. Chamra, "Evaluation of CCHP systems performance based on operational cost, primary energy consumption, and carbon dioxide emission by utilizing an optimal operation scheme," Applied Energy, vol. 86, no. 12, pp. 2540-2549, Dec. 2009.

[17] L. Wang and C. Singh, "Stochastic combined heat and power dispatch based on multiobjective particle swarm optimization," International Journal of Electrical Power \& Energy Systems, vol. 30, no. 3, pp. 226-234, 2008. 
[18] B. Mohammadi-Ivatloo, M. Moradi-Dalvand, and A. Rabiee, "Combined heat and power economic dispatch problem solution using particle swarm optimization with time varying acceleration coefficients," Electric Power Systems Research, vol. 95, pp. 9-18, Feb. 2013.

[19] P. K. Roy, C. Paul, and S. Sultana, "Oppositional teaching learning based optimization approach for combined heat and power dispatch," International Journal of Electrical Power \& Energy Systems, vol. 57, pp. 392-403, May 2014.

[20] S. S. Sadat Hosseini, A. Jafarnejad, A. H. Behrooz, and A. H. Gandomi, "Combined heat and power economic dispatch by mesh adaptive direct search algorithm," Expert Systems with Applications, vol. 38, no. 6, pp. 6556-6564, Jun. 2011.

[21] R. Azizipanah-Abarghooee, T. Niknam, M. A. Bina, and M. Zare, "Coordination of combined heat and power-thermal-wind-photovoltaic units in economic load dispatch using chance-constrained and jointly distributed random variables methods," Energy, Nov. 2014.

[22] T. Guo, M. I. Henwood, and M. van Ooijen, "An algorithm for combined heat and power economic dispatch," Power Systems, IEEE Transactions on, vol. 11, no. 4, pp. 1778-1784, 1996.

[23] F. J. Rooijers and R. A. van Amerongen, "Static economic dispatch for co-generation systems," Power Systems, IEEE Transactions on, vol. 9, no. 3, pp. 1392-1398, 1994.

[24] G. Cardoso, M. Stadler, M. C. Bozchalui, R. Sharma, C. Marnay, A. Barbosa-Póvoa, and P. Ferrão, "Optimal investment and scheduling of distributed energy resources with uncertainty in electric vehicle driving schedules," Energy, vol. 64, no. 0, pp. 17-30, Jan. 2014.

[25] M. Stadler, M. Groissböck, G. Cardoso, and C. Marnay, “Optimizing Distributed Energy Resources and building retrofits with the strategic DER-CAModel," Applied Energy, vol. 132, pp. 557-567, Nov. 2014.

[26] M. Stadler, M. Kloess, M. Groissböck, G. Cardoso, R. Sharma, M. C. Bozchalui, and C. Marnay, "Electric storage in California's commercial buildings," Applied Energy, vol. 104, pp. 711-722, Apr. 2013.

[27] G. Cardoso, M. Stadler, A. Siddiqui, C. Marnay, N. DeForest, A. Barbosa-Póvoa, and P. Ferrão, "Microgrid reliability modeling and battery scheduling using stochastic linear programming," Electric Power Systems Research, vol. 103, pp. 61-69, Oct. 2013.

[28] "DER-CAM official website," 29-Jan-2014. [Online]. Available: http://der.lbl.gov/dercam. [Accessed: 29-Jan-2014].

[29] M. Stadler, A. Siddiqui, C. Marnay, H. Aki, and J. Lai, "Control of greenhouse gas emissions by optimal DER technology investment and energy management in zero-netenergy buildings," European Transactions on Electrical Power, vol. 21, no. 2, pp. 12911309, 2011.

[30] M. Stadler, C. Marnay, G. Cardoso, T. Lipman, O. Mégel, S. Ganguly, A. Siddiqui, and J. Lai, "The $\mathrm{CO} 2$ abatement potential of California's mid-sized commercial buildings," Ernest Orlando Lawrence Berkeley National Laboratory, Berkeley, CA (US), 2009.

[31] F. J. Rubio, A. S. Siddiqui, C. Marnay, and K. S. Hamachi, "CERTS customer adoption model," 2000.

[32] M. Stadler, "Effect of Heat and Electricity Storage and Reliability on Microgrid Viability: A Study of Commercial Buildings in California and New York States," 2009.

[33] C. Marnay, G. Venkataramanan, M. Stadler, A. Siddiqui, R. Firestone, and B. Chandran, "Optimal technology selection and operation of microgrids in commercial buildings," 2007, pp. 1-7. 
[34] G. Cardoso, M. Stadler, M. Chehreghani Bozchalui, R. Sharma, C. Marnay, A. BarbosaPovoa, and P. Ferrao, "Stochastic programming of vehicle to building interactions with uncertainty in PEVs driving for a medium office building," 2013, pp. 7648-7653.

[35] "BHKW-Kenndaten 2011," ASUE Arbeitsgemeinschaft für sparsamen und umweltfreundlichen Energieverbrauch e.V., 2011.

[36] "Technology Characterization: Reciprocating Engines," Environmental Protection Ageny - Combined Heat and Power Partnership Program, Dec. 2008.

[37] E. M. L. Beale and J. A. Tomlin, "Special facilities in a general mathematical programming system for non-convex problems using ordered sets of variables," $O R$, vol. 69, pp. 447-454, 1970.

[38] "AIMMS Modeling Guide - Integer Programming Tricks." Paragon Decision Technology B.V, 2012.

[39] "IBM developerWorks - official forum," 10-Jan-2014. [Online]. Available: https://www.ibm.com/developerworks/community/forums/html/public?lang=en. [Accessed: 10-Jan-2014].

[40] B. A. McCarl, A. Meeraus, P. van der Eijk, M. Bussieck, S. Dirkse, P. Steacy, and F. Nelissen, "McCarl GAMS user guide," GAMS Development Corporation, 2013.

[41] GAMS Development Corporation, "GAMS_ A User's Guide." GAMS Development Corporation, 2010.

[42] M. Stadler, M. Groissböck, G. Cardoso, A. Müller, and J. Lai, "Encouraging Combined Heat and Power in California Buildings," Ernest Orlando Lawrence Berkeley National Laboratory, Berkeley, California, USA, 2013.

[43] "California Commercial End-Use Survey (CEUS)," California Energy Commission, Mar. 2006.

[44] "Technology Characterization: Microturbines," Environmental Protection Agency Climate Protection Partnership Division, Mar. 2002.

[45] "Technology Characterization: Fuel Cells," Environmental Protection Agency Combined Heat and Power Partnership Program, Dec. 2008. 


\section{CVs}

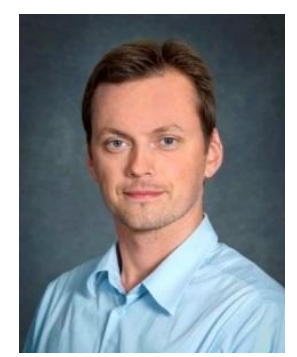

Christian Milan is currently pursuing the $\mathrm{Ph} . \mathrm{D}$. degree in thermal engineering from the Department of Energy Technology at Aalborg University, Denmark. He received the M.Sc. degree in 2010 in industrial engineering and management from the University of Flensburg, Germany. He spent a research internship at Berkeley Lab in 2013. His main research interests are focused on investment planning and operation of distributed energy systems, Net Zero Energy Buildings and residential supply systems based solely on renewable sources.

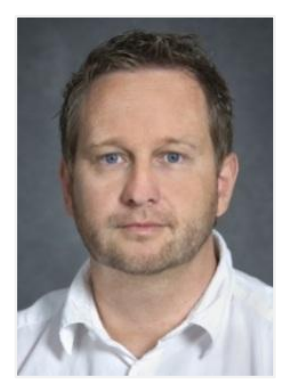

Michael Stadler is a Research Scientist at Lawrence Berkeley National Laboratory, California, USA. He studied at Vienna University of Technology, from which he holds a Master's degree in electrical engineering and a Ph.D. summa cum laude in energy economics. He leads the microgrid and distributed energy resources group at Berkeley Lab and is the lead developer of DER-CAM. He is also the founder of the Center for Energy and innovative Technologies (CET) in Austria. Michael has published more than 160 papers, journal papers, reports, as well as five software tools in his 13 year career to date.

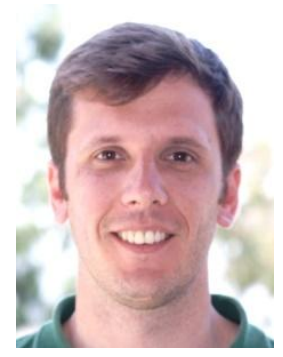

Goncalo Cardoso is a Postdoctoral Fellow at the Lawrence Berkeley National Laboratory working for the Grid Integration Group of the Energy Storage and Distributed Resources Department. He received a M.Sc. in Civil Engineering from Instituto Superior Técnico, Technical University of Lisbon, Portugal, and later Ph.D. in Sustainable Energy Systems also from Instituto Superior Técnico within the MIT-Portugal Program. He focuses on Distributed Energy Resources Investment and Planning, having worked with DER-CAM since 2009, where he had several contributions including the implementation of stochastic capabilities, electric vehicle fleet modeling, critical loads, heat pumps, investment subsidies and feed-in tariffs within the California Self Generation Incentive Program, among others.

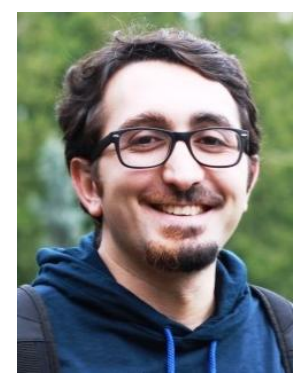

Salman Mashayekh is a Postdoctoral Fellow at the Lawrence Berkeley National Laboratory, Berkeley, CA, USA, working for the Grid Integration Group of the Energy Storage and Distributed Resources Department. $\mathrm{He}$ received his Electrical Power Systems B.Sc. and M.Sc. from University of Tehran, Iran, in 2006 and 2008, respectively, and his Ph.D. from Texas A\&M University, College Station, TX, USA, in 2013. His research interests are in power and energy management methods in microgrids and buildings, electrical and cyber security in smartgrids, and applications of optimization in power and energy systems. 


\section{Figure captions}

Fig. 1. SANKEY diagram indicating energy flows in DER-CAM

$\Rightarrow$ Intended for colour reproduction on the web

$\Rightarrow$ Intended for black-and-white in print

Fig. 2. Schematic representation of DER-CAM

$\Rightarrow$ Intended for colour reproduction on the web

$\Rightarrow$ Intended for black-and-white in print

Fig. 3. Maximal electrical efficiencies for natural gas powered ICEs

$\Rightarrow$ Intended for colour reproduction on the web

$\Rightarrow$ Intended for black-and-white in print

Fig. 4. Electrical efficiencies for a typical natural gas powered ICE in part load

$\Rightarrow$ Intended for colour reproduction on the web

$\Rightarrow$ Intended for black-and-white in print

Fig. 5. Schematic of the binary approach choosing efficiencies based on installed capacity and operational load level at each time step $t$

$\Rightarrow$ Intended for colour reproduction on the web

$\Rightarrow$ Intended for black-and-white in print

Fig. 6. Schematic of the approach based on SOS variable declarations to choose efficiencies changing with installed capacity and operational load level at each time step $t$

$\Rightarrow$ Intended for colour reproduction on the web

$\Rightarrow$ Intended for black-and-white in print

Fig. 7. Schematic of the implementation of the approach using SOS and binary variables into DER-CAM

$\Rightarrow$ Intended for colour reproduction on the web

$\Rightarrow$ Intended for black-and-white in print

Fig. 8. Electrical efficiencies for natural gas powered Micro Turbines

$\Rightarrow$ Intended for colour reproduction on the web

$\Rightarrow$ Intended for black-and-white in print

Fig. 9. Electrical efficiencies for natural gas powered Phosphoric Acid FC

$\Rightarrow$ Intended for colour reproduction on the web

$\Rightarrow$ Intended for black-and-white in print

Fig. 10. Accumulated optimal unit capacities for the four investigated buildings 
$\Rightarrow$ Intended for colour reproduction on the web

$\Rightarrow$ Intended for black-and-white in print

Fig. 11. Accumulated hours of operation for all buildings at relevant load levels compared by applied modelling approach

$\Rightarrow$ Intended for colour reproduction on the web

$\Rightarrow$ Intended for black-and-white in print 